\title{
可湿法加工有机小分子发光材料研究进展
}

\author{
陆天华 $a, b$ 霍延平*,a,b方小明 $a, b$ 欧阳新华 $*, c$ \\ $\left({ }^{a}\right.$ 广东工业大学轻工化工学院 广州 510006) \\ ${ }^{b}$ 中国科学院上海有机化学研究所 有机氟化学中国科学院重点实验室 上海 200032) \\ ( ${ }^{c}$ 中国科学院宁波材料技术与工程研究所 宁波 315201)
}

\begin{abstract}
摘要 综述了近年来国内外可湿法加工有机小分子发光材料的研究状况，对可湿法加工有机小分子发光材料按发光颜 色进行分类, 对其分子结构特点、热稳定性、电学性质、光电学性质、发光效率等进行介绍. 并介绍了可湿法加工有 机小分子发光材料的设计方法及发展趋势.
\end{abstract}

关键词＼cjkstart湿法加工; 有机小分子; 发光材料

\section{Progress of Solution-Processable Organic Small Molecular for Light Emitting Materials}

\author{
Lu, Tianhua ${ }^{a, b}$ \\ Huo, Yanping ${ }^{*, a, b}$ \\ Fang, Xiaoming ${ }^{a, b}$ \\ Ouyang, Xinhua ${ }^{*, c}$ \\ $\left({ }^{a}\right.$ School of Chemical Engineering and Light Industry, Guangdong University of Technology, Guangzhou 510006) \\ $\left({ }^{b}\right.$ Key Laboratory of Organofluorine Chemistry, Shanghai Institute of Organic Cheimstry, \\ Chinese Academy of Sciences, Shanghai 200032) \\ ( ${ }^{c}$ Ningbo Institute of Material Technology Engineerring, Chinese Academy of Sciences, Ningbo 315201)
}

\begin{abstract}
This paper systematically reviews the recent advance in the research and development of solution-processable small molecular light emitting materials. The research finding will be categorized into different emission color and materials as long as their corresponding performances including chemical structure, thermal properties, photology properties, photoelectric properties and luminance efficiency are summarized and discussed. Finally, some method on molecular design and the development tendency on solution-processable smOLEDs are introduced.
\end{abstract}

Keywords solution-processable; organic small molecular; light emitting materials

自从 Tang 等 ${ }^{[1]}$ 在 1987 年报道了高效率的小分子异 质结有机发光二极管(OLED)以来, OLED 由于其在平板 显示方面潜在的应用而受到越来越多研究者的广泛关 注. 第一个达到市场要求的有机发光显示是基于真空蒸 镀的技术来实现的，同时，聚合物 OLED 技术也在不断 的发展，尤其是效率和使用寿命在过去的几年中已经得 到了很大的改善. 真空蒸镀具有显著的优点, 对于实现 高效率多层发光器件的制备是比较方便而有利. 然而, 真空蒸镀所需的设备与工艺比较复杂, 材料利用率低、 时效性差, 仅能用于制备小尺寸 OLED, 而制备大尺寸 OLED 时容易出现薄膜不均匀、硬度低、牢固性差等缺 点, 这很大的限制了其在大面积全色显示方面及商业化
上的应用和推广. 而湿法加工技术例如溶液旋涂的特点 在商业化的应用方面显得较为明显. 它是一种器件制备 容易，可实现低成本、工艺相对简单的薄膜制备技术. 通常，分子量很高的有机聚合物通过溶液加工的方法制 备成膜，然而，由于聚合物本身存在的缺陷，如不明确 的分子结构和不确定的分子量等方面，使其重复性、稳 定性较差, 这在一定程度上限制了聚合物在发光器件方 面的应用. 小分子 OLED (smOLED) 通常使用真空蒸镀 进行加工，或掺入高分子主体材料中以实现溶液加工. 近年来，同聚合物发光材料类似，有机小分子发光材料 也可以实现利用溶液加工法形成稳定平整的薄膜，是非 常有应用前景的电致发光材料. 它们结构确定、可控合

\footnotetext{
*E-mail: yphuo@gdut.edu.cn, ouyangxh@nimte.ac.cn

Received January 30, 2013; revised April 25, 2013; published online May 13, 2013.

Project supported by the National Natural Science Foundation of China (Nos. 21172047, 51273209, 21372051).

国家自然科学基金(Nos. 21172047, 51273209, 21372051)资助项目.
} 
成、重复性好、可常规有机化学方法纯化，同时可以无 须掺杂, 实现高效率电致发光器件. 这类小分子材料在 合成上容易修饰，可调节特定官能团和结构单元，从而 实现分子的功能化. 如上所述, 由于其具有确定的相对 分子质量、化学修饰性强、选择范围广、易于提纯、苂 光量子产率高等优点, 因此, 为了抢占市场降低生产成 本, 发展用于可溶液加工 OLEDs 的小分子材料显得尤 为重要 ${ }^{[2 ~ 11]}$. 本文对可溶液加工有机小分子发光材料按 发光颜色进行分类，对其分子结构特点、热稳定性、电 学性质、光电学性质、发光效率等进行介绍. 并介绍了 可溶液加工有机小分子发光材料的设计方法及发展趋 势.

\section{1 蓝光材料}

在小分子发光材料中以蓝光材料最为关键, 这是由 于不仅材料本身可以作为发光层得到蓝光, 还可以向材 料中掺杂其他发光材料得到绿光和红光. 对于全彩 OLED 显示来说, 蓝光的目标是效率达到 $4 \sim 5 \mathrm{~cd} / \mathrm{A}$, CIE 坐标的 $x$ 值在 $0.14 \sim 0.16$ 范围, $y$ 值在 $0.08 \sim 0.15$ 范围. 目前很多材料在色纯度上已可以满足要求, 但在 器件稳定性上还有待提高 ${ }^{[12]}$. 由于带隙较宽, 相比红绿 光材料而言蓝光材料较难获得. 在分子设计上要求蓝光 材料的化学结构具有一定程度的共轭, 但分子的偶极距 又不能太大, 否则光谱容易红移至绿光区.

\section{1 含芴有机分子蓝光材料}

在各种有机电致发光材料中, 芴具有较高的热稳定 性，固体薄膜的苂光量子效率在 $60 \% \sim 80 \%$, 带隙大于 $2.90 \mathrm{eV}$, 因而是一种备受瞩目的蓝光生色团. 芴可在其 2, 7 和 9 位碳上引入不同取代基来得到一系列衍生物, 因而结构上又具有一定可修饰性. 因此, 芴类生色团在 高效稳定的电致蓝光材料、相结构的调整、多功能化、 主体材料、白光材料、有机激光以及有机纳米发光材料 等方面得到了广泛应用, 逐渐成为有机电子学领域的明 星分子 ${ }^{[13 \sim 15]}$.

\subsection{1 含芴和蒽的有机材料}

$\mathrm{Zhu}$ 等 ${ }^{[16]}$ 合成了一系列蒽的衍生物 1a 1d (Scheme 1), 两个蒽由芴桥连接, 蒽的另一端接上电荷传输基团. 并研究了它们热力学, 光学以及电化学性质. 通过在两 个蒽中引入芴和外围功能化芳取代基, 化合物结晶化的 趋势下降, 玻璃化温度升高至 $165 \sim 229{ }^{\circ} \mathrm{C}$. 通过热力 学计算揭示这四个化合物具有非共平面结构, 空间位阻 抑制了薄膜中分子之间的相互作用，防止了固态时分子 堆叠, 从而得到稳定的无定形薄膜, 发光的量子产率也 让人满意. 另外与蒽相连的基团也充当了电荷传输与空 穴的功能. 做成可湿法加工小分子有机发光二极管后,
化合物 $1 \mathbf{a}$ 的最大电流效率达 $2.0 \mathrm{~cd} / \mathrm{A}, \mathrm{CIE}$ 坐标为 $(0.15$, $0.13)$, 非常接近美国电视标准委员会蓝光标准. 研究者 相信这种设计策略能够应用于蓝光纯度更高的 OLED 显示器苂光材料中.
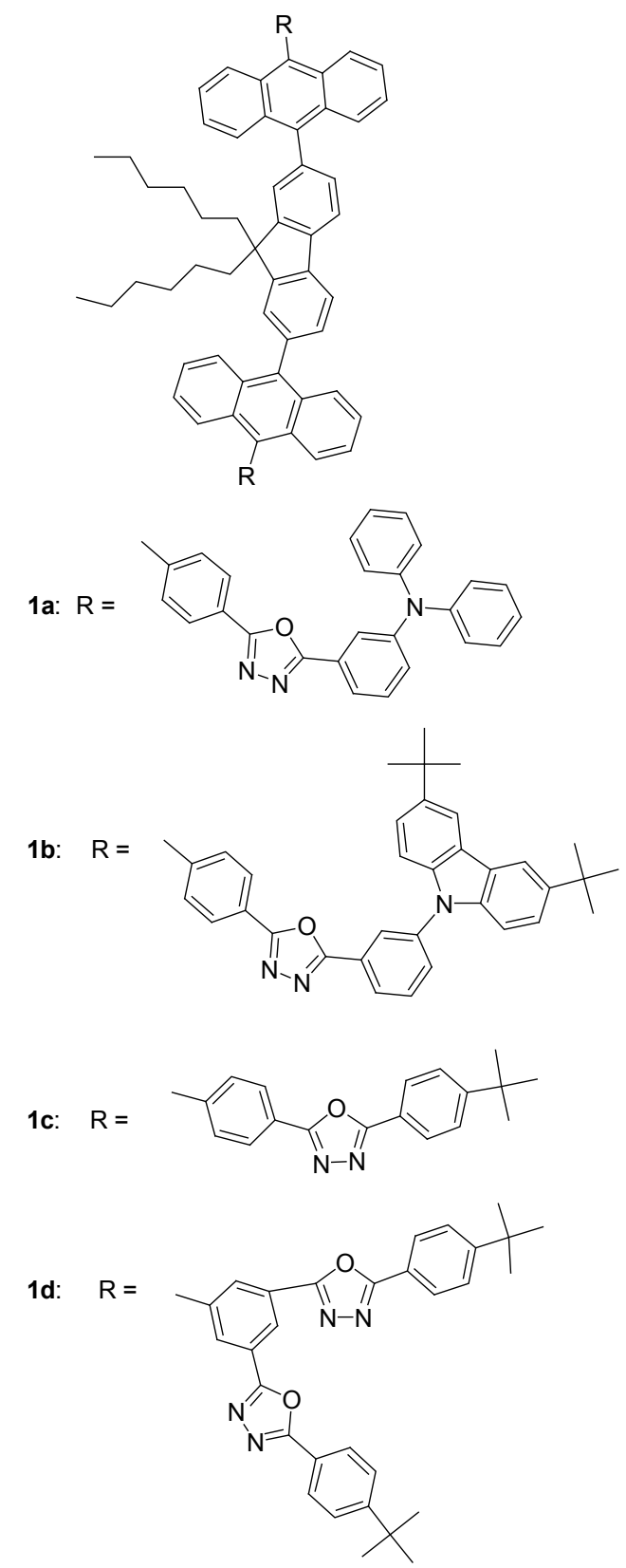

\section{Scheme 1}

\subsection{2 含芴和萠的有机材料}

萠 $^{[17]}$ 是一个相当好蓝光发色团，其在 $310 \sim 340 \mathrm{~nm}$ 区域有相当强的 UV 吸收，荧光发射区域约在 $360 \sim 380$ $\mathrm{nm}$ ，但自身有产生激子发射的趋势，导致并不适合应用 于有机电致发光器件中. 然而萠是优良的电子受体, 虽 然本身存在缺陷但其衍生物可以大大改变器件的性能, 萠与芴的恰当组合可以开发出性能优良的蓝光材料; 萠 
与咔唑或芳胺结合会是一种优良的空穴传输材料; 萠与 硅等结构相连可以开发出优良的主体材料. 尤其是萠与 芴的组合让人看到了高效蓝光材料的希望, 随着研究的 深入会有更多更好的萠的衍生物被开发出来, 而且通过 不断的修饰相信在器件结构简化方面萠的衍生物也会 大有可为. Hwang 等 ${ }^{[18]}$ 使用萠和二烷基芴合成了可溶液 加工深蓝发光分子 2 (Scheme 2). 这种分子可溶于一般 的有机溶剂, 旋涂后能形成平滑的薄膜. 分子 $\mathbf{2}$ 薄膜的 最大紫外-可见吸收和 PL 发射对比于分子 2 溶液由于分 子间平面的相互作用产生更多红移. 将薄膜做成结构为 ITO/PEDOT:PSS/emitter/1,3-bis(3,5-dipyrid-3-yl-phenyl)benzene $(\mathrm{BmPyPB}) / \mathrm{LiF} / \mathrm{Al}$ 的器件后, 激发层使用分子 2 : PVK $(1 ： 9)$ 得到 CIE 坐标为 $(0.14,0.07)$ 的深蓝色发 光器. 器件最大亮度, 最大量子效率以及电流效率分别 为 $500 \mathrm{~cd} / \mathrm{m}^{2}, 0.7 \%$ 和 $0.44 \mathrm{~cd} / \mathrm{A}$.

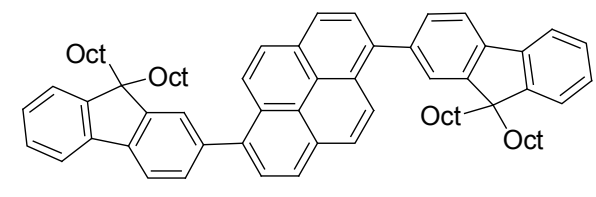

2

Scheme 2

\subsection{3 含螺芴材料}

庞大的螺旋荡结构, 特别是双螺茀, 由于具有独特 的分子构型而成为广泛应用的一类光电功能材料. 在有 机半导体中引入螺旋芴结构可以提高热稳定性、形态稳 定性和载流子迁移率, 而在十字形的双螺芴中引入多环 芳烃是压制 $\pi-\pi$ 堆积的有效方法, 并对器件的发射行为 有很大影响 ${ }^{[19]}$.

Shi 等 ${ }^{[20]}$ 通过总结发现被螺芴基团取代的嘧啶衍生 物由于其高的电子亲和力以及邻位 $\mathrm{C}-\mathrm{H}$ 键的相互作用 较少而很适合作为蓝光发光材料, 于是他们合成了一系 列嘧啶派生物, 将螺䓄与不同嘧啶取代基结合得到具有 独特性能的新型材料 $\mathbf{3 a} \sim 3 \mathbf{e}$ (Scheme 3). 通过研究它们 的物理及光学性质表明具有优异的热力学稳定性和良 好的蓝色发光性能. 通过单晶 $\mathrm{X}$ 射线检测分析, 发现 $3 \mathrm{a}, 3 \mathrm{~b}, 3 \mathrm{e}$ 分子中存在芳香基团与 2-胺基嘧啶骨架的氢 键作用以及分子内 $\pi-\pi$ 共轭、 $\mathrm{C}-\mathrm{H} \cdots \pi$ 超共轭作用, 这 些作用可能会对整个分子共轭平面有显著影响. 这些化 合物中, 3e 最大量子产率达 $63 \%$, 玻璃化温度达 $307{ }^{\circ} \mathrm{C}$. 咔唑 ${ }^{[21]}$ 是典型的富电子基团, 因此咔唑衍生物具 有良好的空穴传输能力和高发光能力, 而且由于咔唑基 团是大的刚性平面结构, 基团运动困难, 可以有效地提 高化合物的玻璃化转变温度 $\mathrm{Tg}$. 因此咔唑衍生物是一 类具有高 $\mathrm{Tg}$ 、高发光强度以及良好空穴传输性能的材

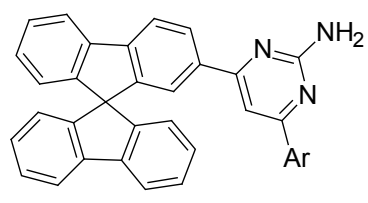

$3 a \sim 3 e$

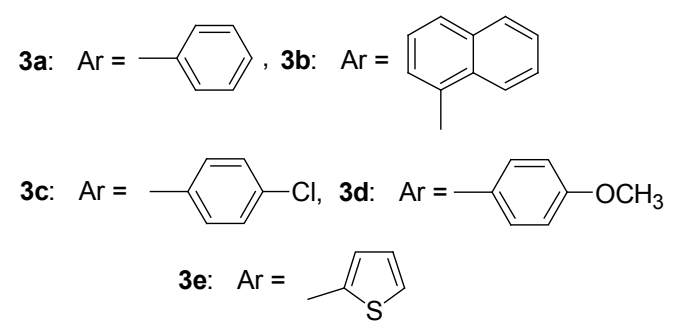

Scheme 3

料. $\mathrm{Ye}$ 等 ${ }^{[22]}$ 设计了一种新型的可溶以咔唑和双螺芴为 基础的无定形分子 4 (Scheme 4). 结构与功能关系分析 表明分子 3 是一种高度扭曲的非共平面分子构型. 最高 占据轨道(HOMO) 以及最低未占轨道(LUMO)分别位于 咔唑与芴环上，这种分离有助于实现高效的空穴和电子 传输性能. 同时该分子的几何特性有效避免了分子之间 $\pi$ 系统的相互作用, 抑制结晶, 增强了薄膜的形态学稳 定性. 利用这种化合物作为主体材料掺入 FIrpic，做成 固溶体高效磷光 OLED. 它具有优异的形态学稳定性, 高可混和性, 低极性以及高的三重态能隙. 研究者相信 这种分子会对新蓝光材料的设计及器件制作有所启示.

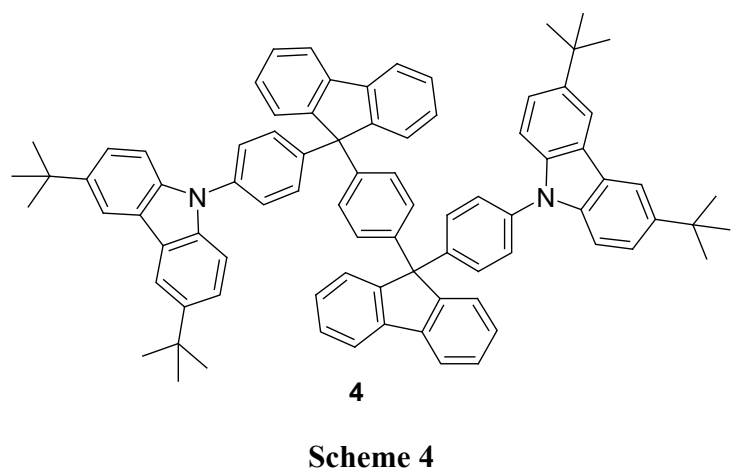

\section{2 含磷类材料}

在有机共轭材料中引入磷原子是一种有效改善材 料光电性能的方法, 因为磷原子一方面可以通过其 $\mathrm{d}$ 轨 道与 $\pi$ 共轭体系间的 $\sigma-\pi$ 相互作用来改变材料的电子结 构; 另一方面可以通过氧化硫化或与金属配位等手段进 行修饰, 从而能在较大范围内调控材料的光电性能. 含 磷的有机 $\pi$ 共轭材料由于其独特的结构特点和多样化的 性能，在有机电致发光材料中显示出了巨大的应用潜 力. 磷杂环戊二烯、二噻吩并磷杂环戊二烯、磷芴和磷 杂聚苯撑乙烯等材料可为 $\pi$ 共轭体系提供新的共轭骨 架;亚氨基膦类材料可作为空穴传输材料; DOPO 作为侧 
基引入共轭体系可以调节材料的溶解性和热稳定性; 富 磷烯类材料可以作为电子供体. 目前研究较多的磷杂环 戊二烯和二噻吩并磷杂环戊二烯等材料已经实现了三 基色发射; 磷芴等其他含磷光电功能材料则研究较少, 但其独特的分子结构和光电特性显示出重要的研究价 值. 综上所述, 磷原子的引入为有机光电功能材料的分 子结构设计和光电性能改善等方面的研究提供了广阔 的空间, 有望成为有机电致发光材料研究开发的一个新 的发展方向 ${ }^{[23]}$.

Sapochak 等 ${ }^{[24]}$ 发现二苯磷酰基团的吸电子诱导效 应会降低咔唑基团的 HOMO 和 LUMO, 因此他们在维 持主体材料三重态能量的前提下改进了阴极的电子注 入, 合成了三种新型的咔唑衍生物 $\mathbf{5 a}, \mathbf{5 b}$ 和 $\mathbf{5 c}$ (Scheme 5)作为掺磷有机发光装置的主体材料. 分别将这三种材 料掺入有机金属铱配合物 FIrpic 中, 在电流密度为 13 $\mathrm{mA} / \mathrm{cm}^{2}$ 下得到外部量子效率为 $6 \% \sim 8 \%$, 操作电压小 于 $7 \mathrm{~V}$.

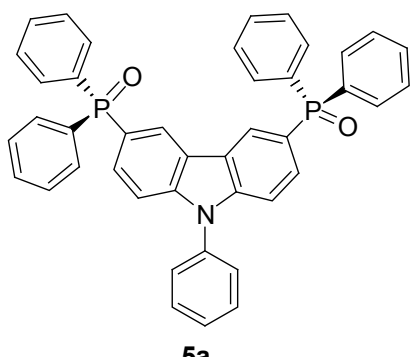

$5 a$
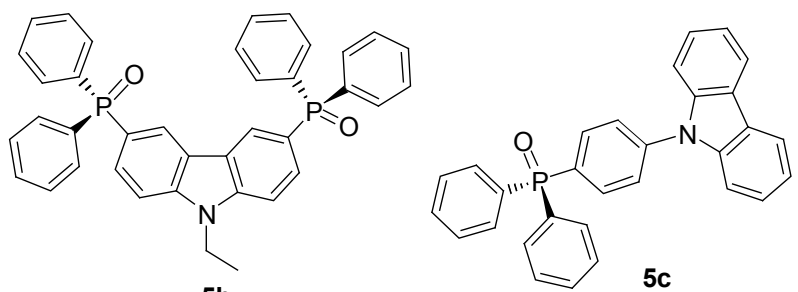

$5 b$<smiles></smiles>

Scheme 5

Jiang 等 ${ }^{[25]}$ 设计了两种可湿法加工的深蓝色 PHOLED 双极主体材料 6a 和 6b (Scheme 6). 由于其独 特的结构特点, 该材料展现出优越的热力学稳定性及高 的三重态能量. 另外, 随着 PO 单元的增加, 材料的玻璃 化温度也逐步提高. 利用这些分子作为主体材料做成磷 光发光 OLED 最大电流效率达 $9.7 \mathrm{~cd} / \mathrm{A}$, 对比于其他同 样基于小分子主体的材料而言表现突出.

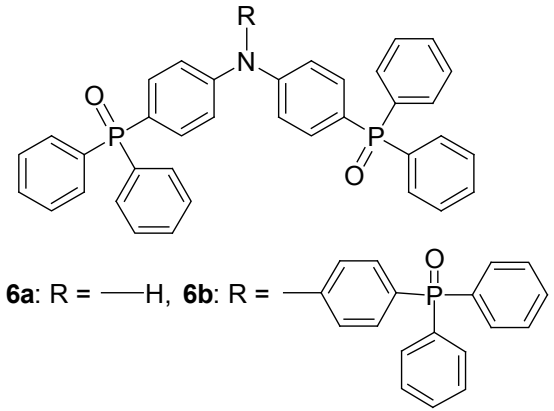

Scheme 6

\section{3 蓝光线形苯乙烯基类寡聚小分子材料}

$\mathrm{He}$ 等 ${ }^{[26]}$ 报道了一种十字型低聚物 7 (Scheme 7), 当 它作为主体材料与客体分子 DPA-DSB 共同作用显示出 优异的性能. 通过苯苯键相连的两个刚性二苯乙烯基苯 的材料 7 光学和电子性能优异, 例如高 PL 效率及大的 键级差，同时中心的二苯基核可以容许两个苯乙烯沿着 二苯基键自由旋转, 使得分子构象多样相对灵活多变, 因此 7 展现出很好的成膜性和大的客体材料负载能力. 材料 7 能有效的分散客体 DPA-DSB. 使用 DPA-DSB 掺 杂到 7 中作为有机发光装置的蓝光发光层, 最大电流效 率为 $12.2 \mathrm{~cd} / \mathrm{A}$, 量子效率为 $6.2 \%$, 光功率效率为 6.39 $1 \mathrm{~m} / \mathrm{W}$, 最大亮度为 $17350 \mathrm{~cd} / \mathrm{m}^{2}$.

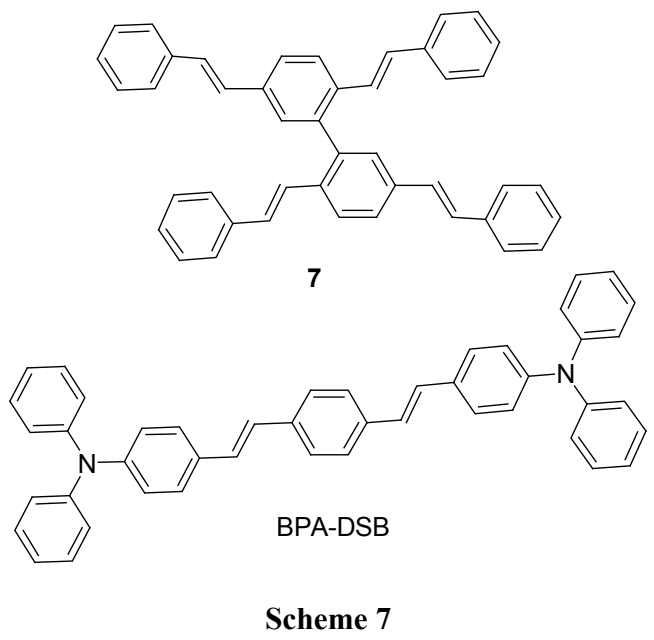

Zhang 等 ${ }^{[27]}$ 以联苯乙烯为基础, 利用 Wittig-Horner 反应分别引入 $N$-己基吩噻嗪和 $N$-己基咔唑基团, 合成 了 2 种联苯乙烯衍生物 8a, 8b (Scheme 8). 通过一系列 化学结构和性能表征表明: 相对于吩噻溙结构, 咔唑结 构是个刚性的平面结构, 是一个大的共轭体系, 离域电 子更容易被激发后产生苂光; 但是在固体状态，咔唑的 平面结构使得化合物 8b 更容易堆砌, 易导致荧光淬灭. 因此, 引入吩噻嗪结构, 对于提高固体薄膜器件的荧光 效率是有利的. 所合成的两个化合物在紫外光激发下均 能发射高亮度荧光; 具有较高的热稳定性, 化合物 $8 \mathrm{a}$ 和 
$8 \mathrm{~b}$ 均具有较高的热分解温度, 失重 $5 \%$ 的温度分别是 377 和 $430{ }^{\circ} \mathrm{C}$, 为制作高稳定性器件创造了条件; 两个 化合物均不能结晶, 易溶于二氯甲烷等有机溶剂, 并且 容易成膜, 非常适合于旋涂法制备 OLED 器件; 其中含 吩噻嗪基的化合物在熔融或冷却过程中均能观察到近 晶 $\mathrm{A}$ 型液晶织构, 可望用于制备直接发射偏振光的发光 器件.

8a: $R=$

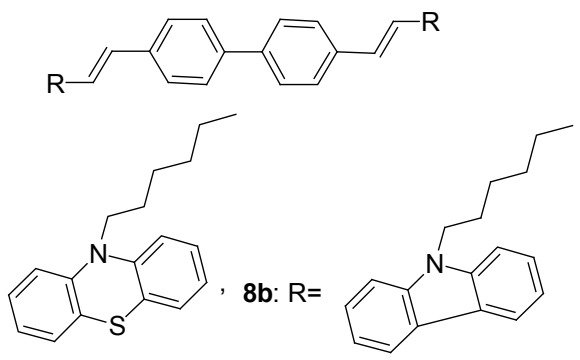

Scheme 8

\section{4 蓝光星形及 X 型低聚小分子材料}

星形寡聚芴可通过简单的有机纯化方法得到, 并且 具有高度支化的树枝型结构, 能够阻止分子间的近距离 排列及空间重新取向，因此能压制聚集，而且可在溶液 中加工形成高质量的无定形薄膜, 改善发光性质. 另外, 通过选择合适的核心和共轭臂长度可对星形寡聚芴的 光电性质进行精细调节. 因此星形寡聚芴在有机电致发 光器件的应用方面要比线性寡聚物或聚合物更具优势.

Liu 等 ${ }^{[28]}$ 报道了一类星型低聚物 9a $\sim 9 c$ (Scheme 9), 该类型低聚物包含一个完整的二苯甲基桥连三苯胺核 心以及低聚芴长臂. 研究者对它们的热力学光学及物理 化学性质进行研究. 这些材料显示出较高的玻璃态转化 温度(约在 $123 \sim 129{ }^{\circ} \mathrm{C}$ ) 以及良好的薄膜生长能量. 这 些材料无论在溶液还是薄膜都能激发出深蓝光. 由于连 有低聚荡, 化合物的器件性能得到明显提升. 含有 9c

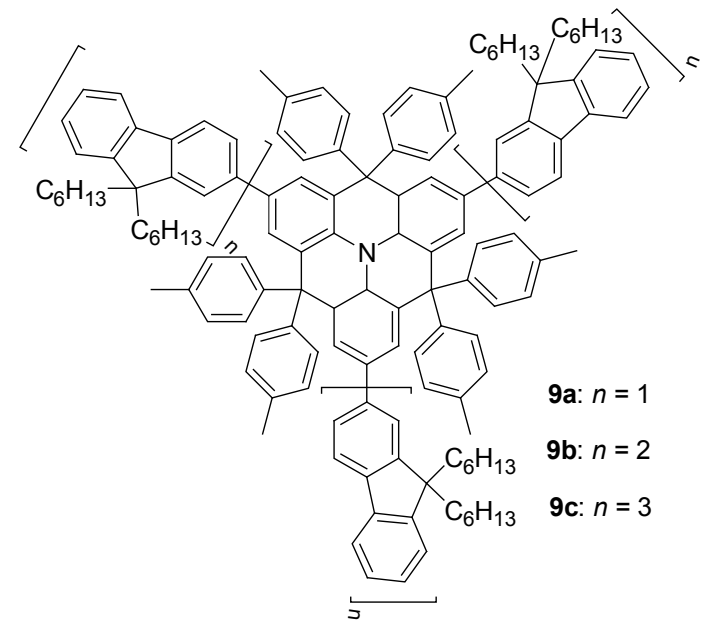

Scheme 9
的双层发光器件最大电流效率为 $3.83 \mathrm{~cd} / \mathrm{A}$. 最大外部 量子效率为 $4.19 \%$. CIE 坐标为 of $(0.16,0.09)$. 是目前湿 法加工星形低聚物非掺杂深蓝 OLEDs 的最高值.

近年来，具有拓扑学特殊结构 $\mathrm{p}$-共轭分子的合成与 表征引起了研究者们的广泛兴趣. 这些分子展现出高的 电化学及光学活性, 它们容易形成无定形玻璃态固体, 同时它们对质子及金属十分敏感. 为此 Sun 等 ${ }^{[29]}$ 合成了 一种新型基于葱衍生物的 $\mathrm{X}$ 型可湿法加工低聚物 $\mathbf{1 0}$ (Scheme 10). 其玻璃态转化温度高于 $200{ }^{\circ} \mathrm{C}$ 并且具有 优异的空穴传输性能. 这种低聚物也同时用作器件的发 光层发出蓝光. 当做成器件后最大发射峰为 $478 \mathrm{~nm}$, 启 亮电压低至 $3.5 \mathrm{~V}$. 然而该装置效率比较低, 最大电流 效率为 $0.1 \mathrm{~cd} / \mathrm{A}$, 最大外部量子效率为 $0.043 \%$. 加入了 电子传输层后, 在 $11 \mathrm{~V}$ 时其最大亮度为 $4549 \mathrm{~cd} / \mathrm{m}^{2}$, 最 大电流效率增加至 $2.32 \mathrm{~cd} / \mathrm{A}$.

2011 年 Sun 等 ${ }^{[30]}$ 又合成了两种含有葱和荡单元的 $X$ 型低聚物 11a, 11b (Scheme 11). 测试显示其具有高光 致发光效率, 热力学稳定性和优异的溶解性. 可以很容 易将其旋涂在联三嗪电子传输层上得到蓝色有机发光 二极管, 在操作电压为 $10 \mathrm{~V}$ 下, 得到的器件的最大亮度 为 $3650 \mathrm{~cd} / \mathrm{m}^{2}$, 最大电流效率为 $0.69 \mathrm{~cd} / \mathrm{A}$.

\section{5 蓝光树枝状有机小分子材料}

树枝状低聚物是规则的支化大分子，能够对功能基 团如生色团或电子给/受体组分进行精确排列, 还能够 通过核一支化链及表面基团调节其光电及加工性质，而 且支化链可减少核与周围分子之间的相互作用，有效地 抑制聚集体及激基缔合物的形成. 另外，树枝状聚合物 的分子内能量转移效率非常高, 因此合成树枝型蓝光材 料成为目前的研究热点之一[11 33].

Wang 等 ${ }^{[34]}$ 合成了可湿法加工的树枝状的小分子 $\mathrm{G} 0$ 化合物 12 (Scheme 12), 由于采用了树枝状的分子结 构设计，有效的阻止了材料在薄膜中的荧光淬灭，同时 引入的苯乙炔基团改善了材料的电子注入/传输性能. 将该化合物用溶液法甩膜成膜, 引入 PVK 作为空穴传 输/电子阻挡层的双层器件获得了 $5.3 \mathrm{~cd} / \mathrm{A}$ 的电流效率, 色坐标为 $(0.16,0.09)$, 最大亮度达到 $17000 \mathrm{~cd} / \mathrm{m}^{2}$. 这是 目前报道的效率最高的可湿法加工的深蓝色荧光材料 之一.

Soh 等 ${ }^{[35]}$ 合成了一系列基于环膦腈核可溶性树枝状 分子并用于蓝绿光 OLED 主体材料 13a, 13b (Scheme 13)。该树枝状低聚物制备简单产率高，能溶于一般的 有机溶剂从而进行溶液加工. 无定形而且具有优异的热 力学性质, 能满足 OLED 应用需要. 使用 $\operatorname{Ir}(\mathrm{mppy})_{3}$ 做磷 光发射极电流效率达 $35.3 \mathrm{~cd} / \mathrm{A}$, 光功率效率为 33.5 $\mathrm{lm} / \mathrm{W}$. 


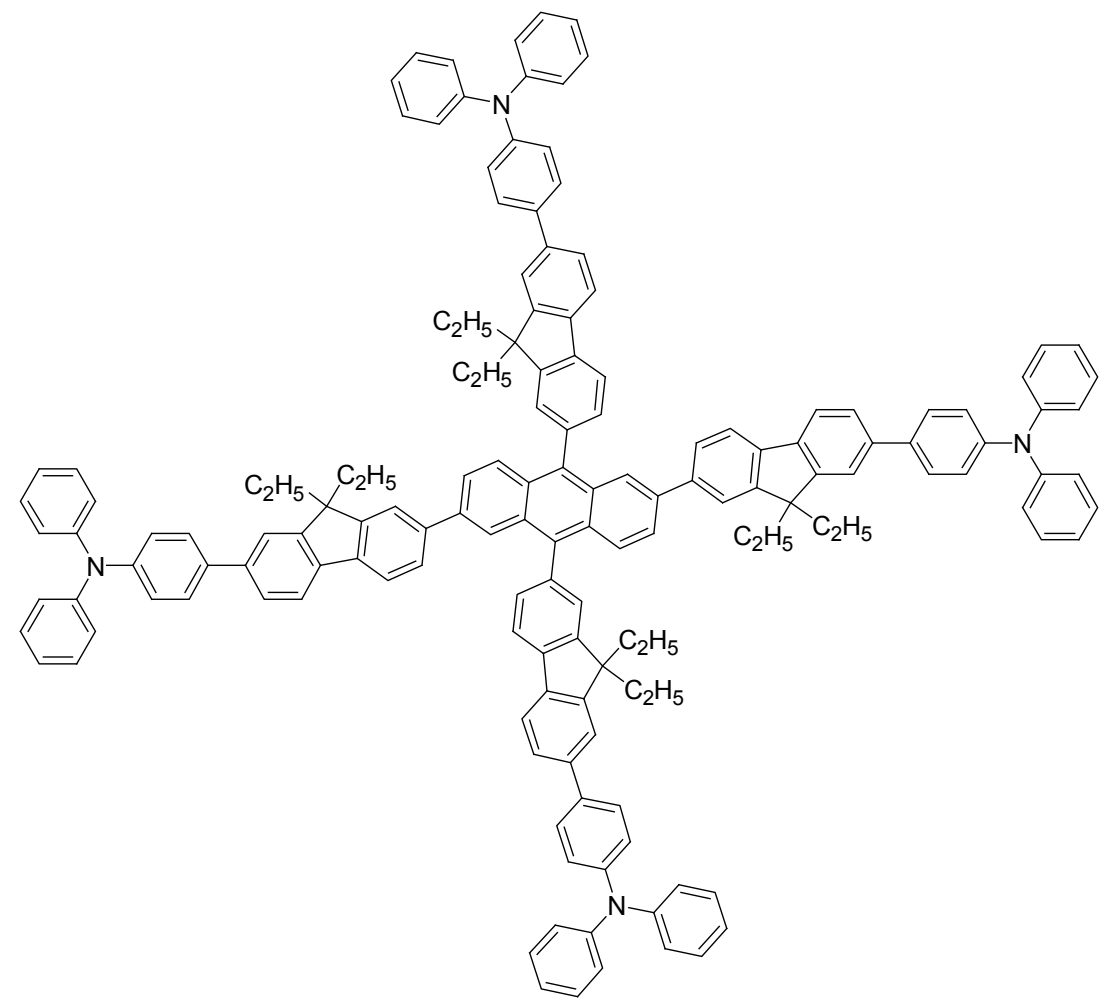

10

Scheme 10
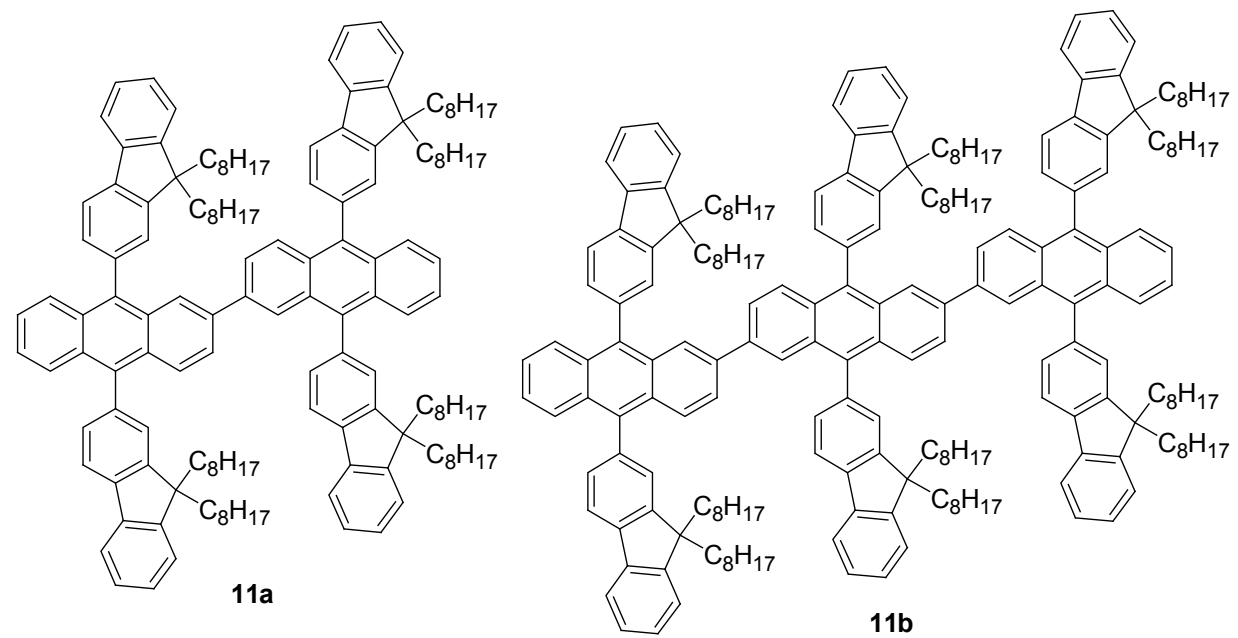

Scheme 11

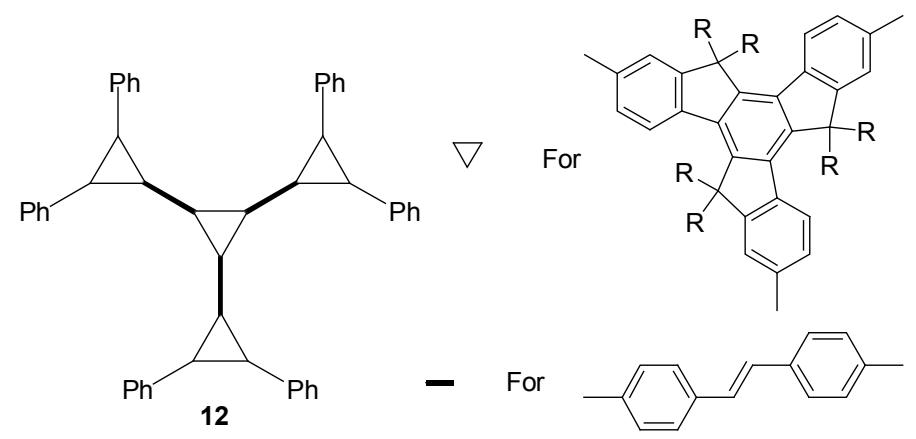

Scheme 12 


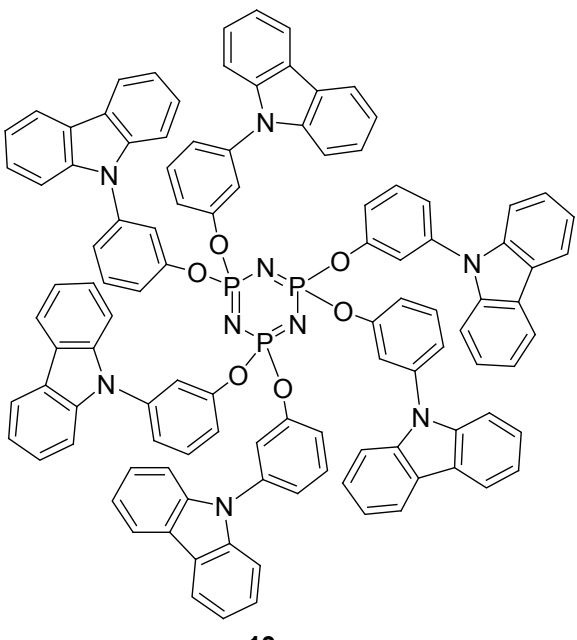

$13 a$

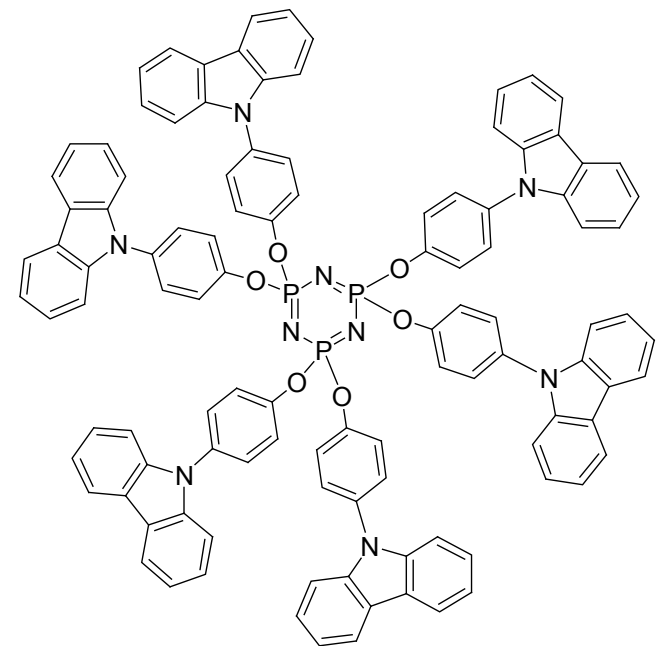

13b

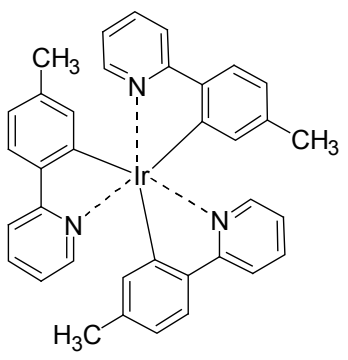

$\operatorname{Ir}(\mathrm{mppy})_{3}$

Scheme 13

\section{6 蓝光金属配合物有机小分子材料}

Fan 等 ${ }^{[36]}$ 以 FIrpic 天蓝光发光材料为框架设计合成 了两种新型磷/硫代铱配合物 14a 和 14b (Scheme 14). 通 过在苯环的 $5^{\prime}$ 位引入磷硫基团是发射峰蓝移至 $460 \mathrm{~nm}$, 同时却保持化合物的高光量子效率, 在溶液中光量子效 率为 $50 \%$. 做成结构为 ITO/PEDOT:PSS/PVK:OXD-7: dopants $/ \mathrm{CsF} / \mathrm{Al}$ 的单层蓝光和白光全溶液加工器件后, 基于 POFIrpic 的蓝光器件最大电流效率为 $11.1 \mathrm{~cd} / \mathrm{A}$. 最大外部量子效率为 $7.1 \%$, 是目前有记录效率最高的 全湿法加工 PhOLED.

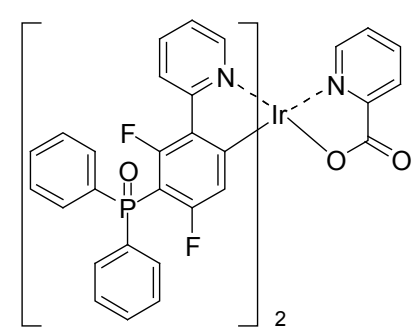

$14 a$

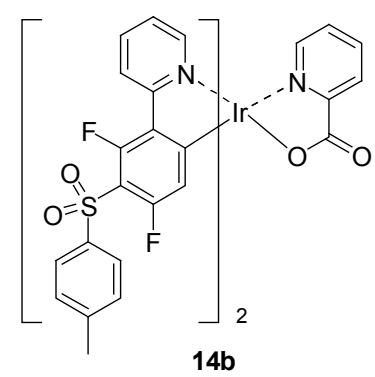

$14 b$
Scheme 14

长久以来, 色纯度是研制高效蓝光可溶性 PHOLEDs 的难题, 虽然早已研究出量子效率超过 $15 \%$ 天蓝色可溶性磷光发光材料, 然而其 $y$ 色坐标高于显示 器应用所需的 0.20 , Yook 等 ${ }^{[37]}$ 使用可溶性发光层化合物 15 和 FCNIrpic (Scheme 15)第一次制成了一种高效的可 湿法加工深蓝 PHOLEDs. 其色坐标为 $(0.14,0.19)$. 最大 量子效率达 $22.1 \%$, 在 $100 \mathrm{~cd} / \mathrm{m}^{2}$ 下量子效率为 $18.9 \%$. 这是首次使用这两种材料作为发光层, 其成功表明这两 种材料作为发光层具有广阔的发展前景.

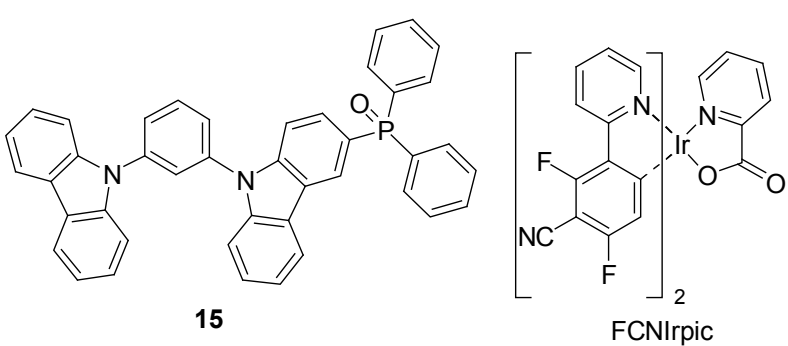

Scheme 15

\section{2 绿光材料}

绿光材料发展相对成熟, 但研究人员依然没有停止 研究的脚步, 他们通过分子修饰可以改善材料的溶解 性, 提高发光效率, 使得绿光材料各种性能更加优异.

\section{1 绿光有机小分子发光材料}

Aizawa 等 ${ }^{[38]}$ 合成了咔唑型湿法加工磷光有机磷光 发光装置主体材料 16a 和 16b (Scheme 16). 两种材料均 在一般有机溶剂中具有优异溶解能力且具有很高的三 重态能量用于抑制激子的磷光激发. 16a 在一般双层 OLED 中光功率效率和外部量子效率分别高于 $30 \mathrm{~lm} / \mathrm{W}$ 和 $13 \%$.

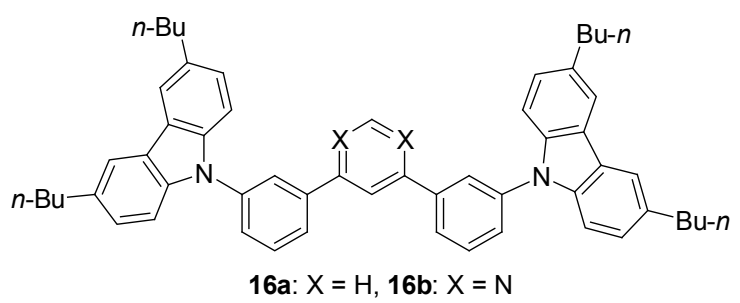

Scheme 16 


\section{2 绿光星形及树枝状低聚小分子发光材料}

$\mathrm{Ge}$ 等 ${ }^{[39]}$ 根据密度泛函理论计算设计合成了一类新 的既含有空穴传输三苯胺基又含有电子传输苯并咪唑 基星型双极主体材料 17a, 17b, 17c (Scheme 17), 通过理 论计算 TIBN 衍生物的能隙, 为设计具有有利 $\mathrm{HOMO} /$ LUMO 能级位置以及预确定三重态能隙增大的分子方 面提供建设性帮助. 将 17a 衍生物 17b, 17c 作为主体材 料分别用旋涂和真空蒸镀方法制得磷光有机发光二极 管, 结果显示, 旋涂 $17 \mathrm{~b}$ 和 $17 \mathrm{c}$ 的装置显示出比真空蒸 镀该材料的装置更好的性能. 旋涂 $17 \mathrm{c}$ 装置亮度达 $47500 \mathrm{~cd} / \mathrm{m}^{2}$, 电流效率达 $27.3 \mathrm{~cd} / \mathrm{A}$, 光功率效率达 7.3 $1 \mathrm{~m} / \mathrm{W}$, 性能表现突出.

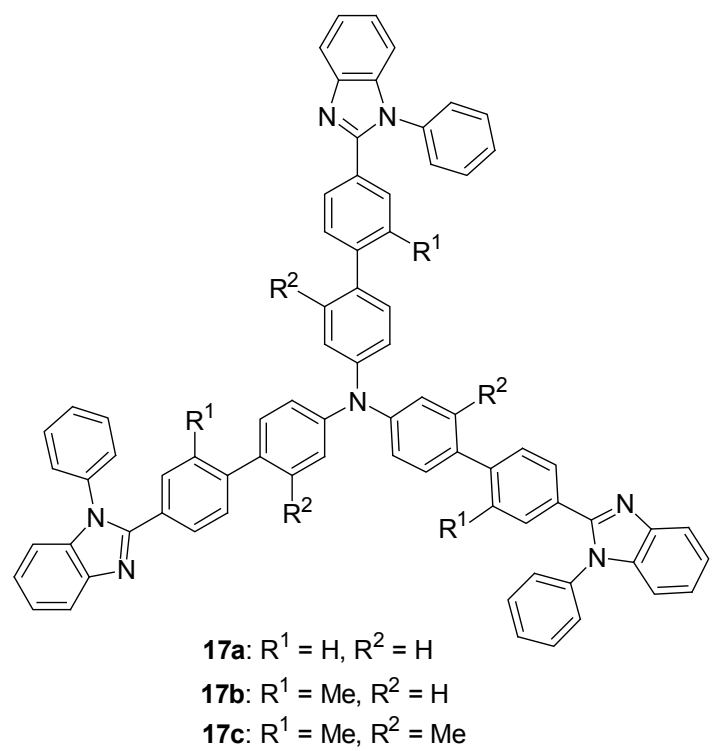

Scheme 17

$\mathrm{Ge}$ 等 ${ }^{[40]}$ 在原有基础上进行改进合成了两种既含有 空穴传输三苯胺基又含有电子传输苯并咪唑基的可溶 液加工双极分子 $18 \mathrm{a}$ 和 $18 \mathrm{~b}$ (Scheme 18). 18a 和 $18 \mathrm{~b}$ 具 有优异的热力学稳定性, 其玻璃态转化温度 $(\mathrm{Tg})$ 分别为 148 和 $144{ }^{\circ} \mathrm{C}$. 其在氮气下分解温度 $(\mathrm{Td})$ 分别为 552 和 $515{ }^{\circ} \mathrm{C}$. 由于具有可变以及星形的结构, 它显示出很好 的在普通有机溶剂中的溶解性, 因而可溶液加工. 使用 $18 \mathrm{a}$ 和 $18 \mathrm{~b}$ 作主体材料掺入 $\operatorname{Ir}(\mathrm{ppy})_{3}$, 旋涂单层结构, 做 成磷光有机发光二极管. 其中 $18 \mathrm{~b}$ 装置的单重态-三重 态能隙比 TBBI 的更大. $18 \mathrm{~b}$ 装置的最大发光效率, 最大 电流效率, 最大光功率效率分别为 $16400 \mathrm{~cd} / \mathrm{m}^{2}, 27.4$ $\mathrm{cd} / \mathrm{A}, 4.5 \mathrm{~lm} / \mathrm{W}$. 在同类单层可溶液加工 OLEDs 中表现 优异.

\section{3 绿光树枝状有机小分子材料}

$\mathrm{Li}$ 等 ${ }^{[41]}$ 以联苯为核, 以低聚咔唑作为树枝合成出一 系列树枝状化合物 19 (Scheme 19). 将该树枝状化合物

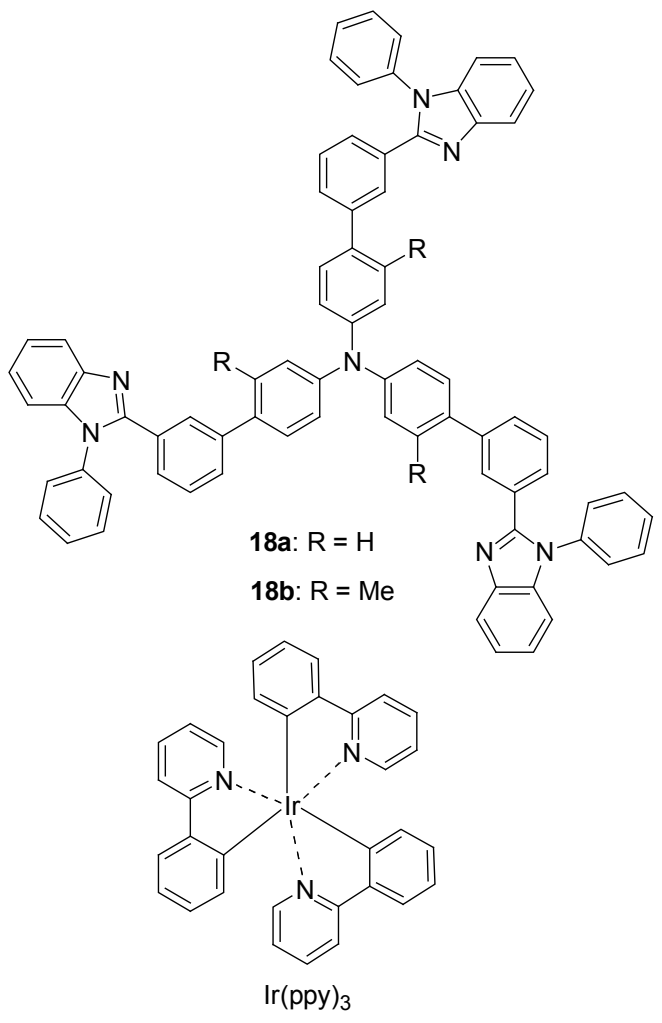

Scheme 18

用于作为 PHOLEDs 主体材料. 配上可溶性的小分子材 料 $\mathrm{CBP}$, 该材料显示出优异的非定型性质, 玻璃态转化 温度达 $376{ }^{\circ} \mathrm{C}$ 并可用于溶液加工. 然而该材料的三重态 能隙较小 $(2.60 \sim 2.62 \mathrm{eV})$, 配上 PVK 后, HOMO 能级大 为提高, 制成了具有优异空穴注入能力和高光功率效率 的绿光 OLEDs. 最大发光效率为 $38.71 \mathrm{~cd} / \mathrm{A}$, 光功率效 率为 $15.69 \mathrm{~lm} / \mathrm{W}$. 是至今报道最有效的溶液加工绿光 PhOLEDs 之一.

\section{4 绿光有机金属配合物小分子发光材料}

Elschner 等 ${ }^{[42]}$ 通过对一系列 $\mathrm{Ga}$ 配合物的旋涂和蒸 镀技术分别制备了一种器件结构相同的双层器件, 通过 对比发现, 旋涂器件和蒸镀器件所得到的效率相当, 例 如使用配合物 20 (Scheme 20)蒸镀器件效率为 $0.55 \mathrm{~cd} / \mathrm{A}$, 而旋涂器件效率为 $0.35 \mathrm{~cd} / \mathrm{A}$, 这种在效率相当的条件 下，采用旋涂技术很大的降低成本，简化制备工艺.

Ryn 等 ${ }^{[43]}$ 成功合成了可用于湿法加工电致发光材料 烷基化铝喹啉衍生物 21 (Scheme 21). 该化合物通过 ${ }^{1} \mathrm{HNMR}$, IR 和 FAB-质谱所证实. 为了评估其光电学性 质，将化合物 21 旋涂于 ITO/PEDOT 基片上制成薄膜激 发层, 双层 $\mathrm{LiF} / \mathrm{Al}$ 用作为电子注入极. 电致发光装置发 射峰为 $509 \mathrm{~nm}$, 属于绿光发射. CIE 色坐标为( 0.31 , $0.52)$. 在原子力显微镜下观察到材料成膜性能良好，表 明其适合用于湿法加工 OLED.

Lee 等 ${ }^{[44]}$ 设计合成了两种铱配合物 $22 \mathbf{a}$ 和 $22 \mathbf{b}$ 


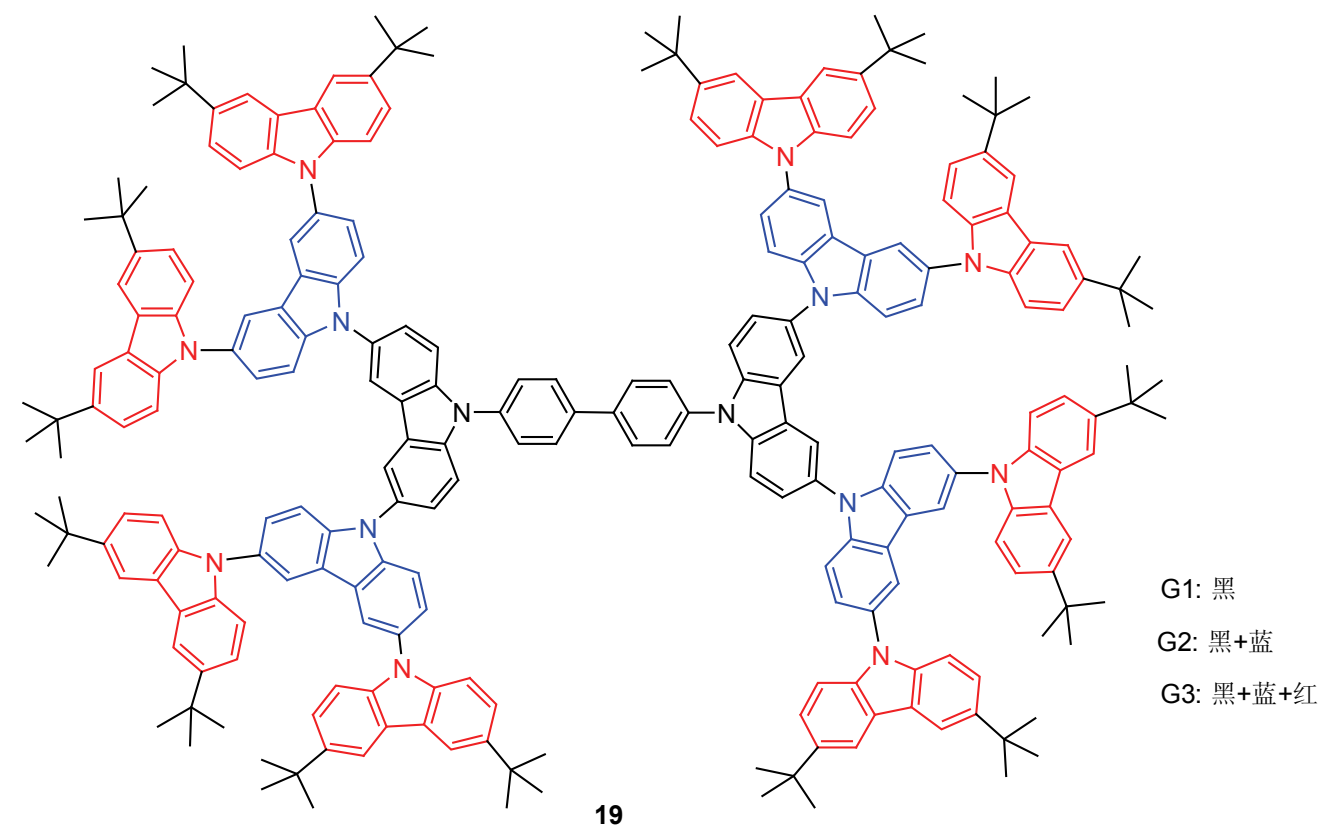

Scheme 19

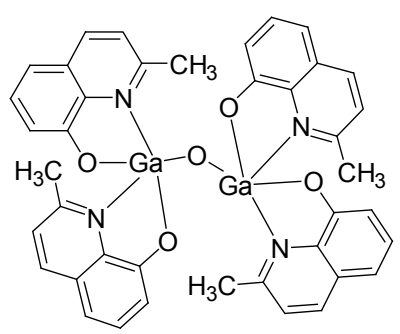

20

Scheme 20

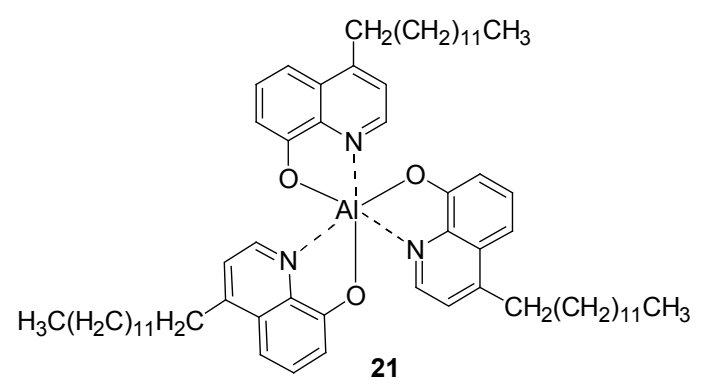

Scheme 21

(Scheme 22), 两种配合物有着相似的结构, 而前者有一 个硅取代基. 从光学和电化学表征中显示它们的性质相 近, 最大发射峰分别 537 和 $531 \mathrm{~nm}$, 能隙分别为 2.33 和 $2.31 \mathrm{eV}$. 而器件性能却有较大差别, 由于将三甲基硅取 代基的引入配体的吡啶环上增强了分子的溶解性和可 加工性, 同时减少了分子间的相互作用. 器件性能分析 显示 22b 的最大电流效率达 $24.5 \mathrm{~cd} / \mathrm{A}$, 而 22a 只有 18.0 $\mathrm{cd} / \mathrm{A}$.

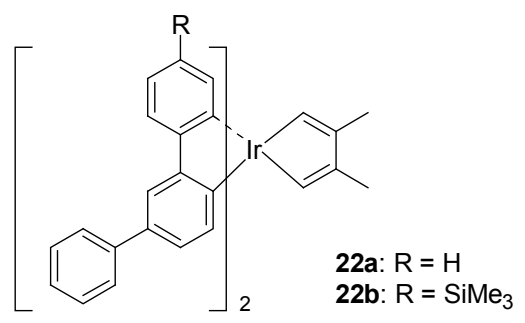

Scheme 22

Hashimoto 等 ${ }^{[45]}$ 合成了一系列高效发光的三聚体铜 (I)配合物 23a 23c (Scheme 23). 三种化合物无论在脱 气的二氯甲烷溶液还是在无定形薄膜上都显示出优异 的光学性能. 前者量子产率 $(\Phi)$ 为 $0.43 \sim 0.60$, 寿命 $(\tau)$ 为 $4.9 \sim 6.5 \mu \mathrm{s}$; 后者量子产率 $(\Phi)$ 为 $0.57 \sim 0.71$, 寿命 $(\tau)$ 为 $3.2 \sim 6.1 \mu \mathrm{s}$. 将化合物 23 制作成传统 OLEDs 测得器件 发绿光, 电流效率为 $65.3 \mathrm{~cd} / \mathrm{A}$, 最大外部量子效率为 $21.3 \%$

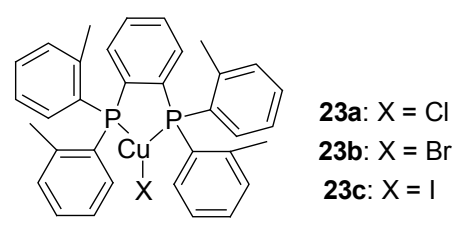

Scheme 23

Huang 等 ${ }^{[46]}$ 设计并测试了一系列新型非共轭功能化 树枝状化合物 24 (Scheme 24). 该系列化合物以苯并咪 唑为基础，被苯基醚分支所包围，通过与三氯化铱环金 
属化反应制得铱配合物. 配合物的发射介于 510 到 530 $\mathrm{nm}$ 之间, 光量子产率介于 0.45 到 0.80 . 做成器件后最大 外部量子效率为 $17.6 \%$, 最大电流效率为 $61.5 \mathrm{~cd} / \mathrm{A}$.

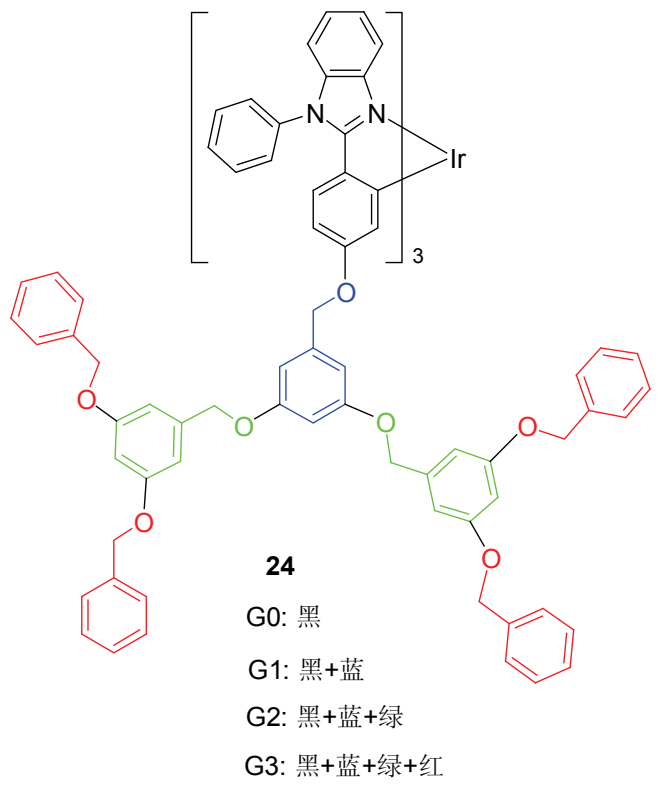

Scheme 24

\section{3 红光材料}

相对于绿光、蓝光材料, 红光材料的设计上存在挑 战性，造成这种状况的原因有很多，但可以归纳为：(1) 要想获得红光发射, 其带隙要比较小, 即产生红光发射 的化合物的能隙很小. 这为红光材料的设计增加了困 难; (2)红光材料体系中, 存在较强的 $\pi-\pi$ 相互作用, 或者 具有强的电荷转移(charge transport, CT)特性, 均会加剧 分子的聚集, 易导致荧光淬灭; (3)制备器件时, 多作为 掺杂客体使用, 掺杂技术虽然解决了器件制备的问题, 但也带来其自身无法克服的问题(主、客体材料之间的能 量匹配、相分离等). (4)人的眼睛对光的敏感度不同, 对 绿光最为敏感, 对红光最弱.

\section{1 红光有机单体小分子发光材料}

Huang 等 ${ }^{[47,48]}$ 研究者通过改进 Stile 偶联反应, 设计 并合成了一系列红色荧光材料. 其中苯并噻二唑衍生物 25a 和 25b (Scheme 25) 都具有良好的溶解性、成膜性、 比较高的固态光致发光效率, 利用化合物 $25 \mathrm{a}$ 制备蒸镀 器件, 用 NPB 作为空穴传输层, $\mathrm{AlQ}_{3}$ 作为电子传输层, 获得了饱和红光发射, 最大电流效率达到 $3.0 \mathrm{~cd} / \mathrm{A}$, 利 用化合物 25b 采用溶液法制备了 ITO/PEDOT/PVK/材料 $25 \mathrm{~b} / \mathrm{Ba} / \mathrm{Al}$ 结构器件, 该器件的最大电流效率为 2.1 $\mathrm{cd} / \mathrm{A}$, 外量子效率达到 $2.74 \%$, 色坐标为 $(0.65,0.35)$, 是 效率较高的小分子非掺杂荧光材料之一.

Zhou 等 ${ }^{[49]}$ 合成了以连欱为端基的红光小分子可溶<smiles>CCCCCCc1cc(-c2ccc(-c3cc(CCCCCC)c(-c4cc(-c5cccc6ccccc56)cc(-c5cccc6ccccc56)c4)s3)c3nsnc23)sc1-c1cc(-c2cccc3ccccc23)cc(-c2cccc3ccccc23)c1</smiles>

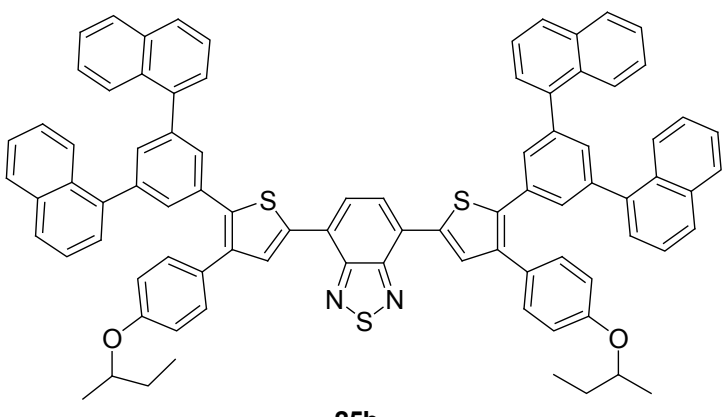

25b

Scheme 25

液加工苂光材料 26a 和 26b (Scheme 26), 非共平面的连 荟基团由于两个荎平面的夹角使得分子可以形成无定 形态, 并且增加溶解性. 这种结构在蓝光化合物中已经 有所应用，但是还没有相应的红光化合物的合成. 由紫 外和荧光光谱可以看出, $26 \mathrm{a}$ 也就是联萘在中间的结构, 在固态膜中峰相对于溶液基本上没有红移，这是因为高

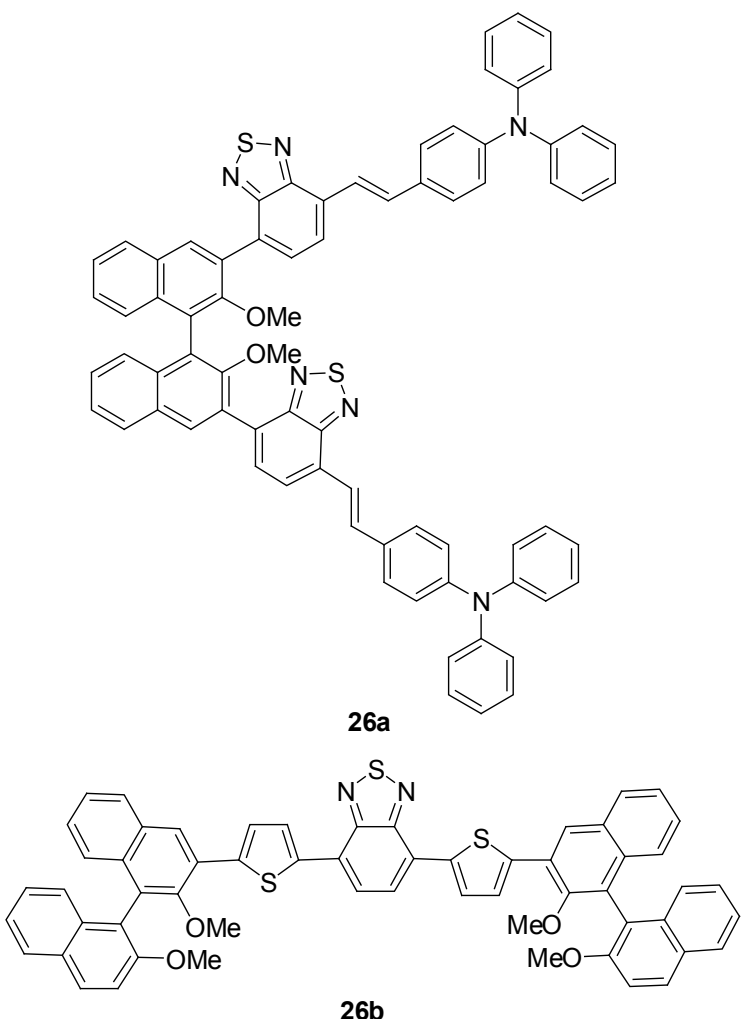

Scheme 26 
度扭曲的结构以及空间位阻使得固态中分子间的相互 作用变弱. 而 26b 联萘在端基的结构则稍有红移. 这几 种材料都是用旋涂的方法制备器件 [ITO/PEDOT: PSS/ HTL(PVK: Poly-TPD)/EML(TBT，材料 26a，或者 $\mathbf{2 6 b})(50 \mathrm{~nm}) / \mathrm{Ca} / \mathrm{Al}$ ], 当使用 $\mathbf{2 6 b}$ 为发光层时, 最大亮度 为 $8315 \mathrm{~cd} / \mathrm{m}^{2}$ 、电流效率为 $1.95 \mathrm{~cd} / \mathrm{A}$ 、启亮电压 $2.2 \mathrm{~V}$.

\section{2 红光线形低聚小分子发光材料}

$\mathrm{Oh}$ 等 ${ }^{[50]}$ 合成及表征了两种新的包含电子和空穴部 分的双极主体材料 27a 和 27b (Scheme 27), 它们的光致 发光和电化学研究表明两种材料都具有电子和空穴传 输能力, 十分适合用于红色电致发光. 通过仅含空穴和 仅含电子装置研究 $27 \mathrm{a}$ 和 $27 \mathrm{~b}$ 的双极传输性质, 使用 27a 的多层溶液加工磷光装置表现在红色电致发光装置 中表现优异. 最大亮度达 $14440 \mathrm{~cd} / \mathrm{m}^{2}$, 电流及光功率效 率达 $21.0 \mathrm{~cd} / \mathrm{A}$ 和 $11.3 \mathrm{~lm} / \mathrm{W}$.

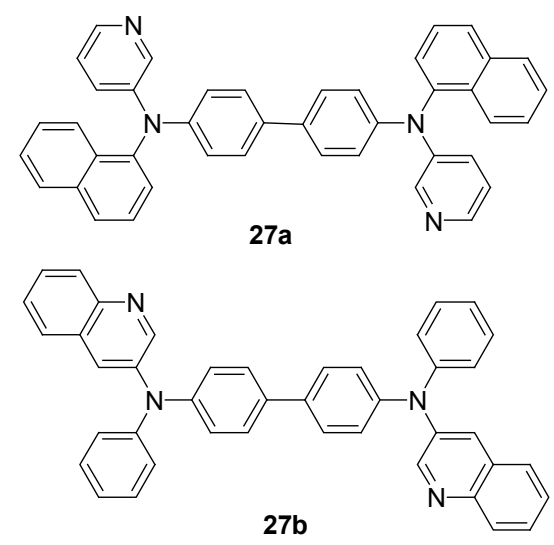

Scheme 27

\section{3 红光星形及树枝状低聚小分子发光材料}

Yang 等 ${ }^{[51]}$ 合成了以三苯胺和苯并噻二唑为基本结 构单元的三类小分子可溶液加工红光材料 $(\mathbf{2 8 a}, \mathbf{2 8 b}$, 28c), 如 Scheme 28. 基本结构是以苯并噻二唑为核, 乙 烯键作为桥键, 三苯胺为端基, 但是端基的选择有一个, 两个或者三个. 这三种化合物在氯苯或甲苯中溶解性都 很好, 超过 $18 \mathrm{mg} / \mathrm{mL}$, 并且热稳定性也非常好. 通过 旋涂法制备的器件 [ITO/PEDOT:PSS(30 nm)/PVK: poly-TPD $(40 \mathrm{~nm}) / \mathrm{EML}(60 \mathrm{~nm}) / \mathrm{Ca}(10 \mathrm{~nm}) / \mathrm{Al}(100 \mathrm{~nm})]$ 当 掺杂浓度为 PVK:poly-TPD (1：1, 质量比)时, 其启亮电 压为 $2.0 \mathrm{~V}$ 、最大亮度是 $12192 \mathrm{~cd} / \mathrm{m}^{2}$ 、最大电流效率是 $1.66 \mathrm{~cd} / \mathrm{A}$.

$\mathrm{Li}$ 等 ${ }^{[52]}$ 合成并研究了一系列新型化合物 $29 \mathbf{a}, \mathbf{2 9 b}$ 和 29c (Scheme 29). 它们的特征是超过 $250 \mathrm{~nm}$ 的大 stokes 位移. 另外, 由于大树枝基团为激发核平面提供 了离域效应, 使得分子可湿法加工. 外部的咔唑基或三 苯胺单元有利于空穴在这些分子薄膜平面上传输. 使用

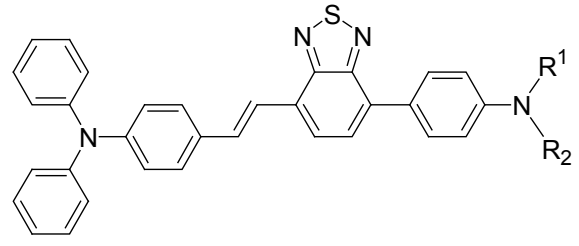<smiles>[R10]C#[R][18O]</smiles><smiles>[R2]=Cc1ccc(-c2ccc(/C=C/c3ccc(N(c4ccccc4)c4ccccc4)cc3)c3nsnc23)cc1</smiles>

Scheme 28

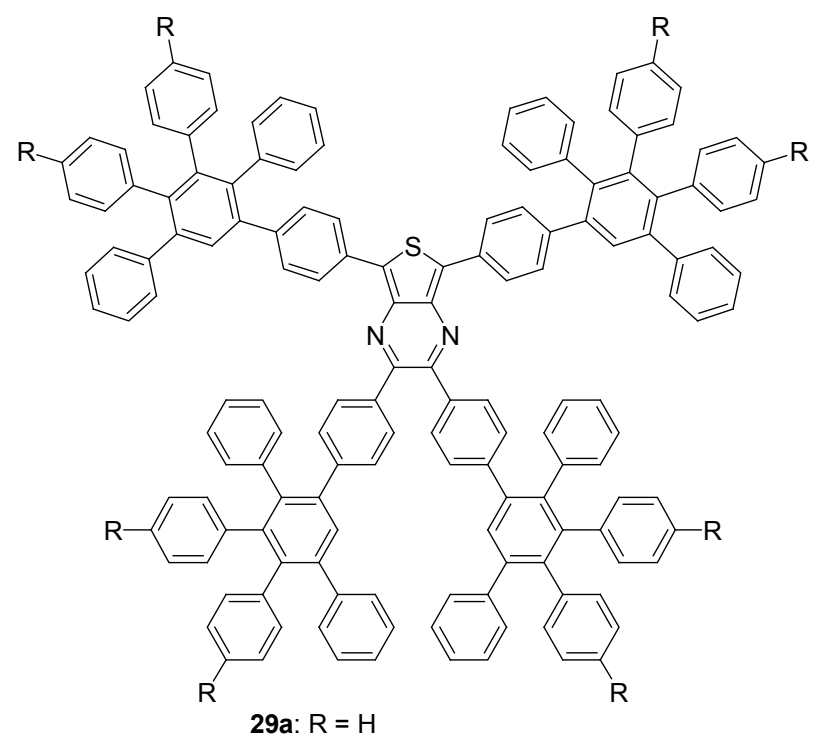

29b: $R=$<smiles>CN(c1ccccc1)c1cccc2ccccc12</smiles>

29c: $R=$

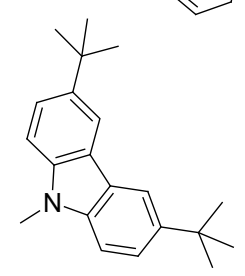

Scheme 29

这些树枝状材料在不掺杂情况下得到了饱和的红色激 发光. 含有咔唑或三苯胺表明基团的树枝状分子 $(29 b$ 和 29c) 亮度达 $1020 \mathrm{~cd} / \mathrm{m}^{2}$, 电流效率达 $0.6 \mathrm{~cd} / \mathrm{A}$, 比不含 该基团的 29a 要高. 


\section{4 红光有机金属配合物发光材料}

Ding 等 ${ }^{[53]}$ 合成了一系列新型红光树枝状功能化低 聚咔唑. 并研究了它们的光物理, 电化学以及光电性能. 该树枝状结构除了可以控制分子间的相互作用外，还参 与了电化学和电荷传输过程. 因此可以通过使用氯仿旋 涂制成电致发光器件. 非掺杂器件最大外部量子效率随 分子代数单调递增. 三代树枝聚合物 30 (Scheme 30)的 外部量子效率高达 $6.3 \%$, 比其零代聚合物提升 30 倍. 将装置结构最优化后得到在亮度为 $100 \mathrm{~cd} / \mathrm{m}^{2}$ 时外部量 子效率达 $11.8 \%$, 电流效率为 $13.0 \mathrm{~cd} / \mathrm{A}$, 光功率效率为 $7.2 \mathrm{~lm} / \mathrm{W}$. 表明这些树枝状分子在可湿法加工红光二极 管中具有广阔前景.

$\mathrm{Li}$ 等 ${ }^{[54]}$ 将卟啉接上 4 个烷基取代的寡聚䓄的基团 后, 当芴的个数为 4 时, 固态的发光峰为 $658 \mathrm{~nm}$ 以及 在 $715 \mathrm{~nm}$ 处有肩峰, 但是没有制备器件. Carl 等 ${ }^{[55]}$ 通过 钯催化 Suzuki-Miyaura 反应合成了一系列含 4 或者 8 个芴的卟啉、酞菁深红光分子 31a, 31b (Scheme 31). 同 时也将咔唑作为端基引入到芴的烷基链上，并且还将锌 原子配位到酞菁分子上, 得到 31c 和 31d. 但是通过吸收 和发射光谱研究发现咔唑的引入对发光光谱没有任何 影响. 而含锌的化合物则发生了蓝移. 化合物材料 31c 制备的掺杂器件 [ITO/PEDOT:PSS/PSBFcopolymer: $31 \mathrm{c} / \mathrm{Ba} / \mathrm{Al}]$ 的最大发光峰位于 $663 \mathrm{~nm}$ 、色坐标为 $(0.70$, 0.27 )、最大外量子效率 $2.5 \%$.

Al-Attar 等 ${ }^{[56]}$ 合成了一族基于一系列铱配合物的高 效可溶电致磷光发光掺合物分子 32a 32d (Scheme 32).
如图, 利用 PVK 作为主体材料掺入该材料制得单层磷 光发光二极管电流效率为 $40 \mathrm{~cd} / \mathrm{A}$, 对应的外部量子效 率为 $12 \%$, 其值在单层磷光器件中位于最高水平, 然而 光功率效率比较低. 改进的方法可以通过选择合适的电 极增强空穴传输以降低启亮电压, 也可以对器件的微腔 进行优化. 同时研究表明作为掺合物的配合物分子跃迁 偶极矩强度对器件的光电性质有显著影响, 可以通过改 变配体的取代基类型和位置对该性质进行优化.

Qin 等 ${ }^{[57]}$ 合成了一系列以铱配合物为核的红色树枝 状磷光发光材料, 分子 33 (Scheme 33) 为其第一代树枝 状分子. 聚亚苯基树枝与三苯胺外壳增强了铱核的激 发, 从而提高了材料薄膜的发光和电致发光性能. 做成 的 PHOLEDs 器件色纯度和效率都表现良好. CIE 坐标分 别为 $(0.68,0.32),(0.66,0.32)$, 和 $(0.63,0.32)$. 三重态能 隙为 $2.64 \mathrm{eV}$, 最大外部量子效率为 $9 \%$.

Zhang 等 ${ }^{[58]}$ 报道了新型铕配合物 34 (Scheme 34), 证明得到一种高效、可溶液加工的基于 OLED 的销配合 物的可能性. 该配合物在亮度为 $100 \mathrm{~cd} / \mathrm{m}^{2}$ 条件下外部 量子效率达 $4.3 \%$. 这是被报道的效率最高的湿法加工 销配合物 OLED 装置. 它的效率衰减速率也比其他报道 的钴配合物要小.

\section{4 黄光材料}

黄光虽然不是原色但它却有一定的重要性. 在高分 辨率全彩的主动有机电致发光 OLED 面板发展趋势中 白光加彩色滤光片是目前极为看好的量产技术，一般都

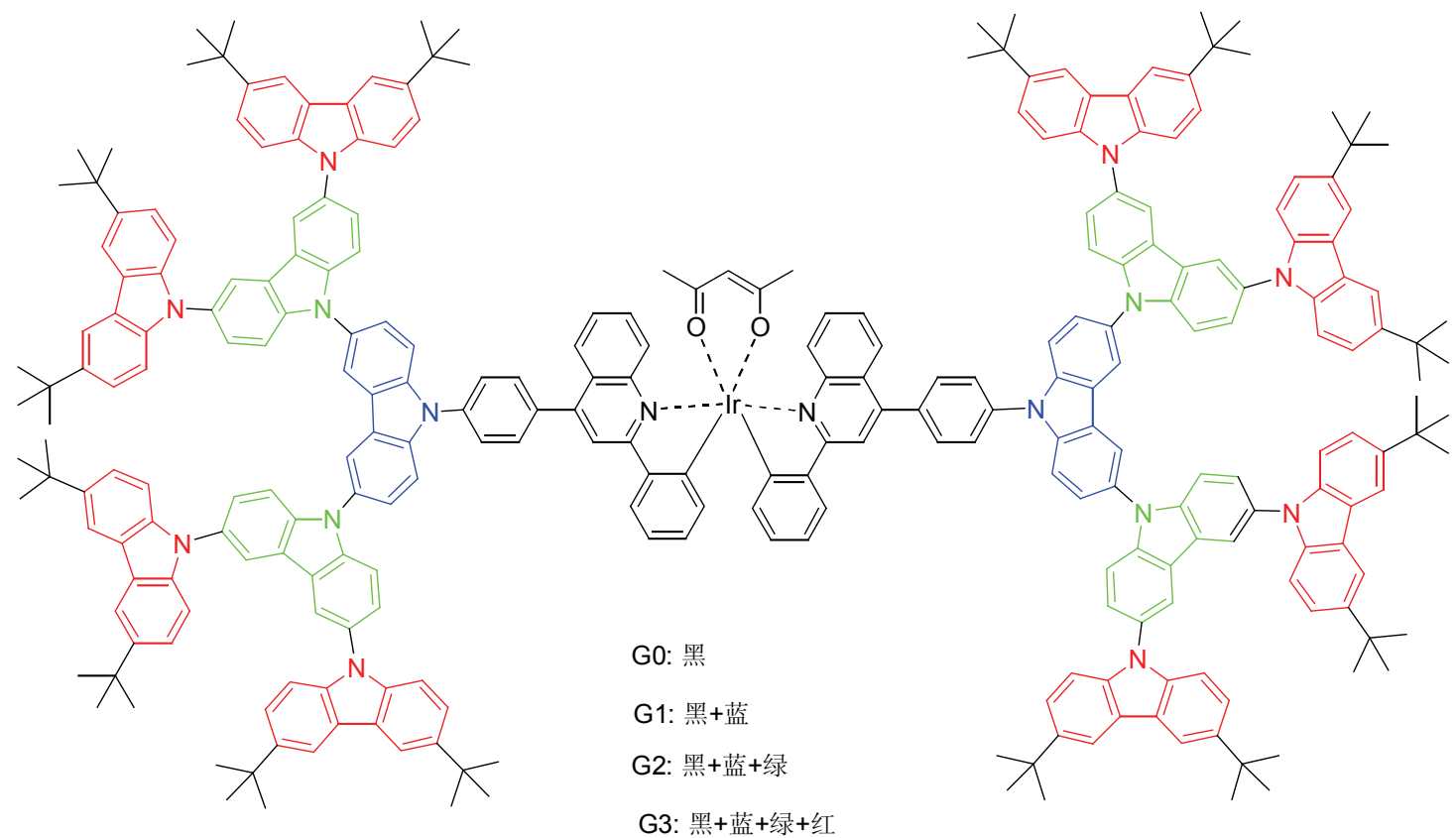




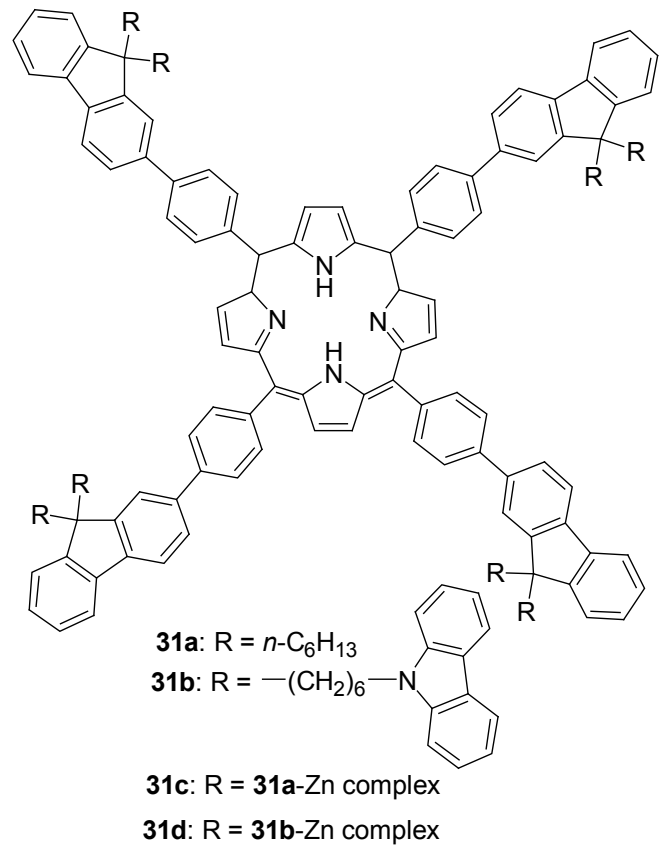

Scheme 31

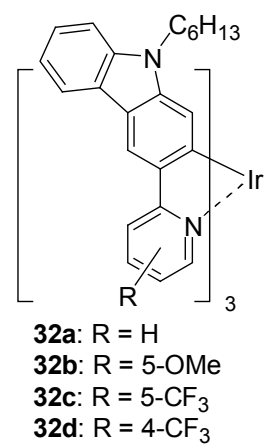

Scheme 32

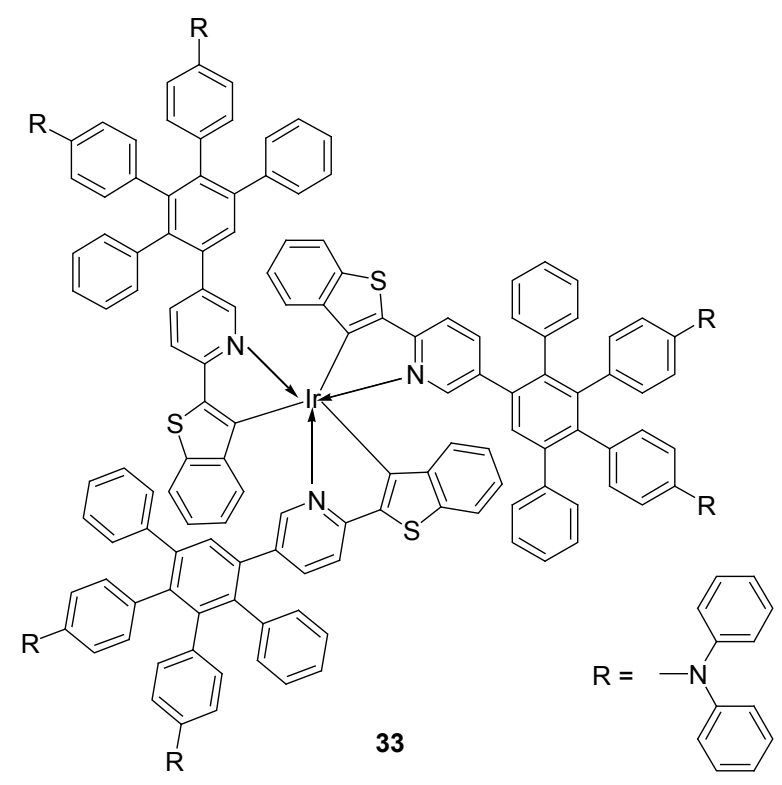

Scheme 33

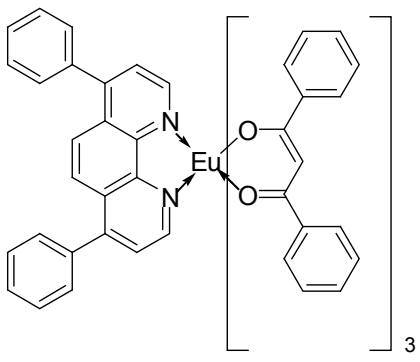

Scheme 34

是引用多层各自发光的混合法如天蓝色加黄光二波段 或红加绿加蓝光三波段的白光组合. 在研发的发光材料 中目前优异的黄光苂光染料比较缺乏, 所以研发优质的 黄光发光材料尤为重要 ${ }^{[59]}$.

Yuen 等 ${ }^{[60]}$ 设计合成了含有芴单元的六种不同系列 (C-N-N)型铂配合物(Scheme 35), 对其光物理性质和电 致发光特性进行了研究. 结果显示: 该类配合物在有机 溶剂中具有良好的溶解性, 可以通过湿法加工制备 OLED 器件. 发射光谱位于 $558 \sim 601 \mathrm{~nm}$ 之间, 主要是 由于受激发的分子内和 MLCT 的三重态引起，最大量子 效率为 0.76. 其中由系列 $\mathbf{3}$ 的配合物 $\mathbf{3 d}$ 制得的黄光 OLED 器件: 其发光效率和最大亮度分别为 $14.7 \mathrm{~cd} / \mathrm{A}$, $27000 \mathrm{~cd} / \mathrm{m}^{2}$.

Ouyang 等 ${ }^{[61]}$ 报道了一种基于二环金属铱(III)配合 物的电致磷光材料 35 (Scheme 36), 将这种配合物制作 高效湿法加工单层电致磷光发光二极管, 其中以 PVK 作为主体材料，掺入 PBD 用于电子传输. 当掺入 $4 \%$ 的 35 分子时, 装置的电流效率为 $30.0 \mathrm{~cd} / \mathrm{A}$, 相应的外部量 子效率为 $15 \%$, 色坐标为 $(0.507,0.486)$. 更重要的是, 产 生磷光时激子并没有受到激发, 这种装置 $568 \mathrm{~nm}$ 有很 广且无特征的发射峰, 该峰的半最大值全宽度 FWHM 达 $83 \mathrm{~nm}$, 这使得分子 35 应用于黄光 OLED 的磷光剂十 分具有前景, 特别是大面积、高效、廉价的黄光 PhOLED.

我们研究小组 ${ }^{[62 ~ 64]}$ 设计了一系列 8-羟基喹啉衍生 物配体 36a, 36b 和 36c (Scheme 37), 将这些配体与锌(II) 离子进行络合形成二聚体、三聚体, 并得到金属配合物 单晶. 通过 ${ }^{1} \mathrm{HNMR}, \mathrm{IR}, \mathrm{MS}$ 和元素分析技术进行了结构 表征, $\mathrm{X}$ 光衍射进行晶体结构分析，紫外滴定模拟了金 属锌与配体的配位过程, 以及测定了它们固态和溶液状 态下的荧光性质. 通过这些数据分析了金属配合物单晶 结构, 空间结构与该金属配合物溶解性及发光性能关 系. 结果为这些金属配合物均能发出黄光, 官能团的改 变能使金属配合物的溶解性及发光性能相应改善. 其中 $\mathrm{X}$ 基团为 $\mathrm{Cl}$ 时对有机物溶解性最好, $\mathrm{X}$ 基团为 $\mathrm{NO}_{2}$ 时溶 解性最差. 结果表明通过对 8-差基喹啉环的 2,5,7 位进 行修饰该系列配合物具有成为可湿法加工高效 OLEDs 材料的潜力. 


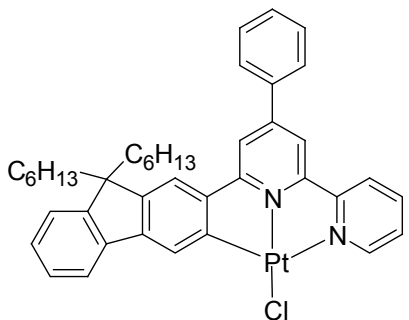

系列 1

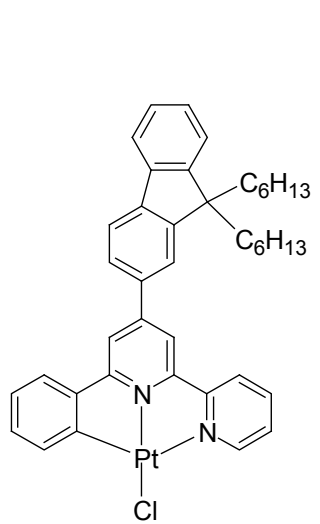

系列 2

\section{2}

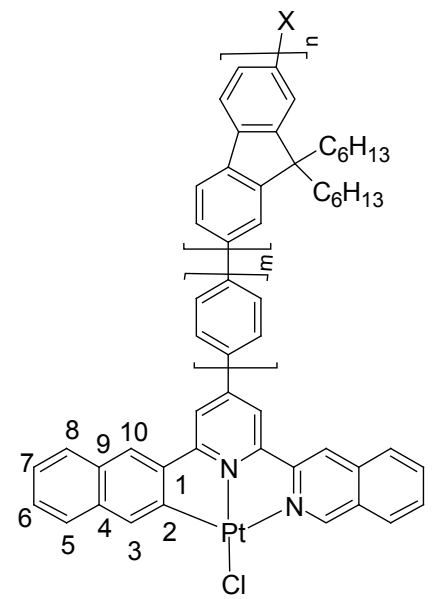

系列 4

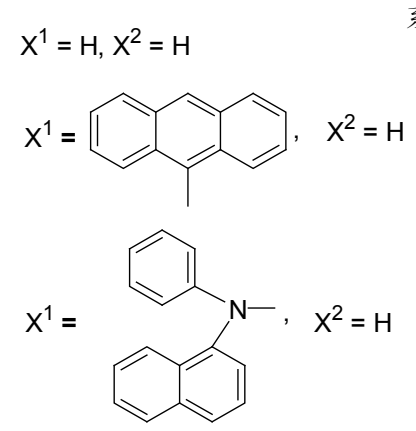

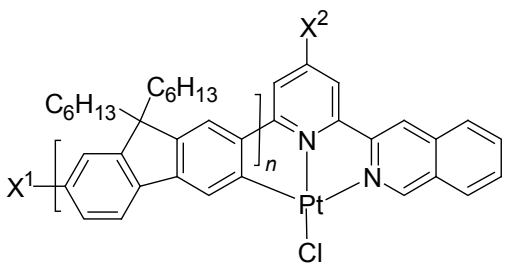

系列 3 $\mathrm{X}^{1}=\mathrm{H}, \mathrm{X}^{2}=\mathrm{Ph}$ $\mathrm{X}^{1}=\mathrm{Br}, \mathrm{X}^{2}=\mathrm{Ph}$ $\mathrm{X}^{1}=\mathrm{H}, \mathrm{X}^{2}=3,5-(t-\mathrm{Bu}){ }_{2} \mathrm{C}_{6} \mathrm{H}_{3}$

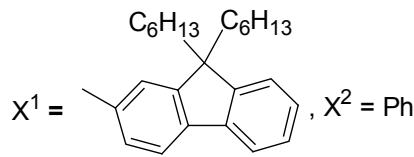

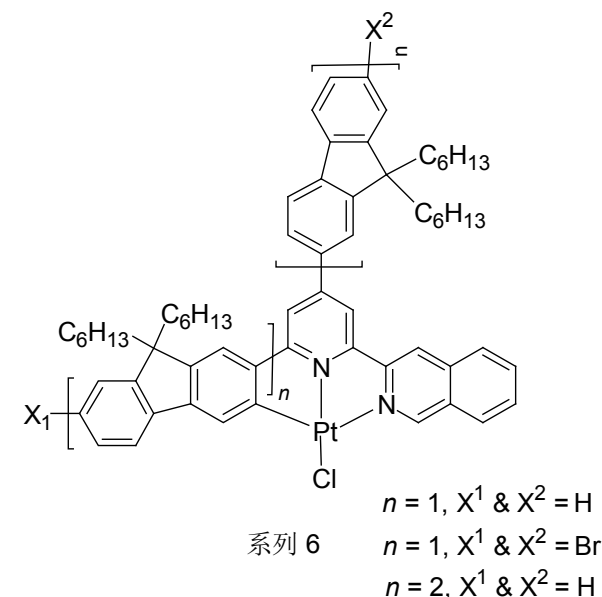

Scheme 35<smiles></smiles>

35<smiles></smiles>

36a: $\mathrm{R}^{1}=\mathrm{R}^{2}=\mathrm{Cl}, \mathrm{R}^{3}=\mathrm{H}$

36b: $R^{1}=R^{2}=F, R^{3}=H$

36c: $R^{1}=R^{3}=N_{2}, R^{2}=H$

Scheme 37

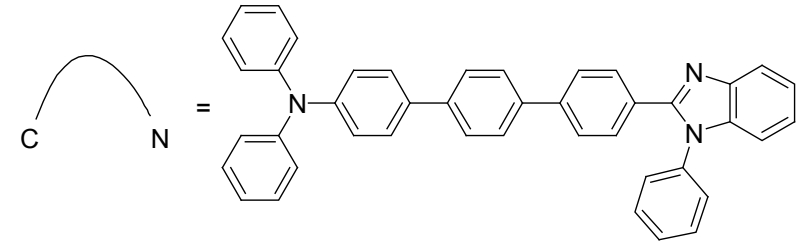

Scheme 36

\section{5 白光材料}

白光是一种白色光源, 主要通过两种互补色或者 红、绿、蓝三基色的混合来产生. 白光 OLED 的颜色质 量主要由色度坐标 $(\mathrm{CIE}$ 坐标)色温和显色指数(CRI)来表 示. 对于高质量的白光, CIE 坐标应尽可能接近色坐标 白点( $0.33,0.33)$, 色温位于 $2500 \sim 6500 \mathrm{~K}$ 之间, CRI 必 须大于 80 . 与单色器件不同的是, 白光 OLED 通常由多 种发光体混合后得到, 其色坐标会随着器件驱动电压或 者亮度的改变而变化; 另外, 由于各种发光体的工作寿 
命不同，白光 OLED 的色坐标也会随着工作时间而改 变, 因此色稳定性也是白光 OLED 至关重要的一个参 数. 发光效率是衡量白光 OLED 性能的另一重要指标, 发光亮度高于 $2000 \mathrm{~cd} / \mathrm{m}^{2}$, 功率效率高于 $100 \mathrm{~lm} / \mathrm{W}$ 的 白光 OLED 具有较高的商用价值. 寿命是白光 OLED 实 现商业化应用重要性能指标, 主要指亮度寿命. 传统白 炽灯平均寿命为 $750 \sim 2500 \mathrm{~h}$, 而荧光灯可达 $20000 \mathrm{~h}$. 为了应用于固态照明, 白光 OLED 的寿命需要达到 $10000 \mathrm{~h}$. 近来寿命长的白光 OLED 已有不少报道. 白光 有机发光器件(OLED)能够产生高效饱和的白光, 且具 有驱动电压低材料柔性好可实现大面积显示等特点, 在 信息显示与固态照明等领域有巨大的应用潜力 ${ }^{[65]}$.

Hou 等 ${ }^{[66]}$ 通过溶液加工方法制成了高性能单层小 分子 WOLEDs. 使用了分子 37 (Scheme 38)作为主体材 料, 该材料在一般有机溶剂中具有良好的溶解性, 并且 具有优异的成膜性能和三重态能隙 $(2.88 \mathrm{eV})$. 配上用于 电子传输的 OXD-7 以及用于构成纯白光两到三种铱配 合物. 经过优化的单层白光装置最大发光效率为 20.8 $\mathrm{cd} / \mathrm{A}(7.2 \mathrm{~lm} / \mathrm{W})$, 最大亮度为 $26600 \mathrm{~cd} / \mathrm{m}^{2}$. 如果加上了 空穴阻挡/电子传输层, 可以获得最大发光效率为 29.6 $\mathrm{cd} / \mathrm{A}(15.6 \mathrm{~lm} / \mathrm{W})$, 最大亮度为 $22300 \mathrm{~cd} / \mathrm{m}^{2}$ 的白光器件.

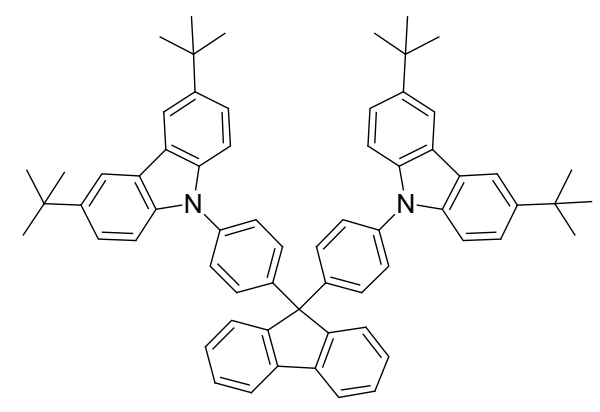

37

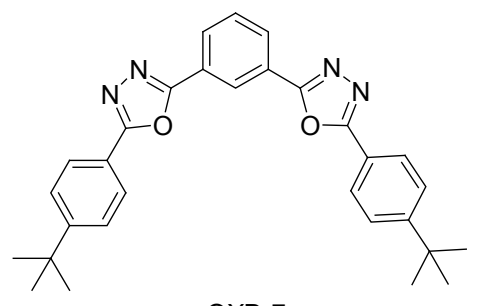

OXD-7

Scheme 38

Liu 等 ${ }^{[67]}$ 使用分子 38 (Scheme 39) 制成结构为 indium tin oxide (ITO)/poly-(3,4-ethylenedioxythiophene): poly-(styrenesuphonic acid) (PEDOT:PSS)/分子 38/1,3,5$\operatorname{tri}(N$-phenylbenzimidazol-2-yl)benzene (TPBi)/LiF/Al 的 纯白光有机发光二极管. 该WOLEDs 的启亮电压为 $6 \mathrm{~V}$, 最大发光效率为 $3.6 \mathrm{~cd} / \mathrm{A}(6 \mathrm{~V})$, 最大亮度为 $204 \mathrm{~cd} / \mathrm{m}^{2}(13$ $\mathrm{V}), \mathrm{CIE}$ 坐标为 $(0.33,0.34)$. 该器件是已报道的溶液加工
WOLEDs 中性能最好的器件之一.

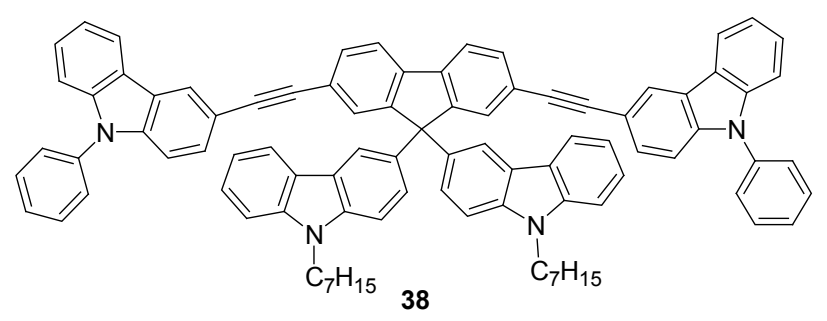

Scheme 39

Wang $^{[68]}$, Zhang ${ }^{[69]}$, Lin $^{[70]}$ 等小组使用 DPVBi 作为主 体材料分别做成了不同结构的器件, 并对器件的性能进 行表征. Wang 使用 NPB:DPVBi 作为混合主体掺入蓝色 及黄色染料, 得到的可溶液加工器件最大亮度为 35822 $\mathrm{cd} / \mathrm{m}^{2}$, 最大发光效率为 $8.3 \mathrm{~cd} / \mathrm{A}$, 光功率效率为 5.3 $\mathrm{lm} / \mathrm{W}$. Zhang 同样使用 NPB:DPVBi 作为混合主体掺入蓝 色及红色染料, 得到可溶液加工器件最大亮度为 13,638 $\mathrm{cd} / \mathrm{m}^{2}$, 发光效率为 $5.7 \mathrm{~cd} / \mathrm{A}$. Lin 使用了双层结构, 将 $\mathrm{BCzVB}$ 掺入 DPVBi 作为蓝光激发层, 将混合物继续掺 入红光 DCJTB 作为白光激发层, 再以 BPhen 作为电子 传输层制得可溶液加工器件, 该器件的 CIE 坐标为 $(0.33,0.33)$, 器件最大亮度为 $22,874 \mathrm{~cd} / \mathrm{m}^{2}$, 最大发光效 率为 $8.10 \mathrm{~cd} / \mathrm{A}$, 光功率效率为 $5.07 \mathrm{~lm} / \mathrm{W}$.

\section{6 小结与展望}

通常情况下高分子使用旋涂成膜，小分子材料通过 蒸镀的方法成膜，即使小分子使用旋涂成膜时也可能因 为玻璃化温度低, 易结晶导致成膜性不好. 鉴于高分子 的一些缺点, 如果能设计合成可溶液加工的高效率的小 分子材料将是一个突破.

在设计形貌稳定的有机可溶液加工小分子时有很 多方法，包括掺杂非共平面的分子，引入大型的刚性基 团比如环氧烷烃，以及扩大分子的大小. 在设计时首先 我们要保证材料是无定形态分子, 因此在设计分子时可 以参考一些原则, Shirota ${ }^{[71]}$ 提出无定形态分子材料的设 计必须遵循以下原则: (1)分子必须具有非平面结构，而 且必须存在不同的构象; (2)在分子结构中引入一些大体 积的基团可以使形成无定形态变得更容易，而且材料热 稳定也会更好; (3)增大分子的尺寸也有助于增加材料玻 璃态的稳定性; (4)在分子结构中引入一些刚性的基团譬 如：联苯基、荎基、芴基、咔唑等基团可以提高材料的 玻璃化转变温度; (5)增大分子尺寸和分子量有助于提高 材料的玻璃化转变温度. 但最终分子是否属于无定形态 分子还要通过 X 射线衍射仪 XRD, 热重分析仪(DSC), 拉曼光谱来鉴定. 但是提高玻璃化温度的手段往往使得 分子溶解性变差, 因此, 在设计分子时要考虑合适的引 
入基团.

通过文中对各种材料的综述我们也不难发现，人们 在设计并合成具有较高溶解度的有机共轭分子时一般 采取以下几个方面的措施: (1)在分子中引入一定长度的 烷基链或烷氧基链. 一般来说, 烷基链(烷氧基链)越长, 增溶效果越好. 但是, 分子中过长烷基链(烷氧基链)的 存在，可能会抑制分子间的 $\pi-\pi$ 堆积，从而降低玻璃化 温度. 因此, 要选择长度适当的烷基链(烷氧基链)增强 分子的溶解性. (2)在分子中引入具有空间多维性的三苯 胺基团. 三苯胺由于具有三维立体结构, 在被引入到分 子当中后，在一定程度上破坏了分子的共轭性，降低了 分子的刚性, 从而增强分子的溶解性. (3)在设计分子的 时候, 多采用单键连接各基团, 尽可能避免共轭双键的 引入. 因为共轭双键的存在会增强分子的刚性, 从而降 低分子的溶解性.

同时从文中还可以看到, 有机电致磷光材料成为了 OLEDs 材料研究的主流. 具有 $\mathrm{d}^{6}$ 和 $\mathrm{d}^{8}$ 电子结构的重金 属原子如铂 $(\mathrm{Pt}) 、$ 铱 $(\mathrm{Ir}) 、$ 锇 $(\mathrm{Os})$, 由于它们强烈的自旋轨 道耦合，使得其配合物的单线态激子和三线态激子混 杂. 一方面三线态具有某些单线态特征, 三线态激子的 对称性被破坏, 缩短了磷光寿命, 减少了磷光猝灭, 增 强了单线态到三线态之间的系间窝跃和磷光效率, 这样 在室温下有可能实现磷光显示. 由于磷光材料在固体中 有较强的三线态猝灭, 一般都是用铱配合物作掺杂客体 材料(guest), 用较宽带隙的材料作掺杂主体材料(host), 通过能量转移或直接将激子陷在客体上发光获得高发 光效率 ${ }^{[72,73]}$.

通过以上综述可以看到, 在最近几年的研究工作 中, 可溶性有机小分子材料得到了快速的发展, 这功劳 离不开科技工作者对这一领域所倾注的大量心血. 可溶 液加工的小分子发光材料在分子设计、化学合成、加工 成膜方式、器件结构等方面都结合了蒸镀小分子和聚合 物各自的优点, 它是一种器件制备容易, 可实现低开启 电压的低成本、工艺相对简单的薄膜制备技术，同时它 具有发光色度纯、荧光效率高、载流子传输性能好以及 发光波长可覆盖整个可见光范围等优点. 覆盖整个可见 波长的高效发光器件也逐渐制备出来. 随着可溶性小分 子研究进一步深入进行, 将有力的推动 OLED 商品化的 进程, 推动显示技术的新一轮变革. 积极开发性能优良 的可溶液加工小分子电致发光材料有着极其重要的理 论和实际意义.

\section{References}

[1] Tang, C.-W.; Van Slyke, S.-A. Appl. Phys. Lett. 1987, 51, 913.

[2] Hu, Y.-C.; Yu, X.-H.; Lv, Y.-M.; Xing, G.-X.; Yu, J.-S. Sci. Technol. Rev. 2010, 17, 100 (in Chinese).
(胡玉才，于学华，吕忆民，邢国秀，于军胜，科技导报, 2010, 17 , 100.)

[3] Mi, B.-X.; Wang, H.-S.; Gao, Z.-P.; Wang, X.-P.; Chen, R.-F.; Huang, W. Prog. Chem. 2011, 23, 136 (in Chinese). (密保秀, 王海珊, 高志强, 王旭鹏, 陈润锋, 黄维, 化学进展, 2011, 23, 136.)

[4] Zhao, C.; Li, H.; Zheng, Y.-P. Dev. Appl. Mater. 2012, 27, 81 (in Chinese).

(赵晨，李昊，郑亚萍，材料开发与应用，2012，27, 81.)

[5] Liu, H.-M.; Zheng, C.-J.; He, J.; Zhang, X.-H. Imaging Sci. Photochem. 2008, 26, 8 (in Chinese).

(刘红梅, 郑才俊, 何鉴, 张晓宏, 影像科学与光化学, 2008, 26, 8.)

[6] Zhong, C.-M.; Duan, C.-H.; Huang, F.; Wu, H.-B.; Cao, Y. Chem. Master. 2011, 23(3), 326.

[7] Cai, M.; Xiao, T.; Hellerich, E.; Chen, Y.; Shinar, R.; Shinar, J. Adv. Mater. 2011, 23(31), 3590.

[8] Huang, H.; Fu, Q.; Zhuang, S.-Q.; Mu, G.-Y.; Wang, L.; Chen, J.-S.; Ma, D.-G.; Yang, C.-L. Org. Electron. 2011, 12(10), 1716.

[9] Lin, X.; Yagai, S.; Kitamura, A.; Hwang, D. R.; Park, S. Y.; Park, Y. S.; Kim, J. J.; Karatsu, T. Synth. Met. 2012, 162(3 4), 303.

[10] He, L.; Duan, L.; Qiao, J.; Zhang, D.; Wang, L.; Qiu, Y. Appl. Phys. A 2010, 100(4), 1035.

[11] Orselli, E.; Maunoury, J.; Bascour, D.; Catinat, J.-P. Org. Electron. 2012, 13(9), 1506

[12] Sato, Y. Semicond. Semimetals 2000, 64, 209

[13] Meunmart, D.; Prachumrak, N.; Keawin, T.; Jungsuttiwong, S.; Sudyoadsuk, T.; Promark, V. Tetrahedron Lett. 2012, 53(28), 3615.

[14] Huo, Y.-P.; Fang, X.-M.; Huang, B.-H,; Zhang, K.; Nie, X.-L.; Zheng, H.-P. Chin. J. Org. Chem. 2012, 32, 1169 (in Chinese). (霍延平, 方小明, 黄宝华, 张焜, 聂晓李, 曾和平, 有机化学, 2012, 32, 1169.)

[15] Liu, F.; Lai, W.-Y.; Tang, C.; Wu, H.-B.; Chen, Q.-Q.; Peng, B.; Wei, W.; Huang, W.; Cao, Y. Macromol. Rapid Commun. 2008, 29, 659.

[16] Zhu, M.; Ye, T.; Li, C.-G.; Cao, X.; Zhong, C.; Ma, D.; Qin, J.; Yang, C. J. Phys. Chem. C 2011, 115(36), 17965.

[17] Xue, Z.; Gao, C.-X.; Lu, M.-B.; Zhang, Y.-X. Guangzhou Chem. Ind. 2010, 38, 31 (in Chinese). (薛震, 高昌轩, 卢明宝, 张玉祥, 广州化工, 2010, 38, 31.)

[18] Hwang, D.-H.; Lee, S.; Kim, J.-H.; Lee, J. Curr. Appl. Phys. 2012, $12, \mathrm{e} 33$.

[19] Mao, B.-X.; Zhang, D.-P.; Hua, X.-Y.; Jiang, H.-J.; Chen, R.-F.; Deng, X.-Y. Prog. Chem. 2010, 22, 2353 (in Chinese). (毛炳雪, 张大鹏，华晓阳，姜鸿基，陈润锋，邓先宇，化学进展， 2010, 22, 2353.)

[20] Shi, Y.; Liu, Q.; Tang, J. Monatsh. Chem. 2011, 142(9), 907.

[21] Yu, T.; Wang, C.-C.; Chen, M.-N.; Chi, Z.-G. New Chem. Mater. 2009, 37, 6 (in Chinese).

(于涛, 王程程, 陈美娜, 池振国, 化工新型材料, 2009, 37, 6.)

[22] Ye, S.; Liu, Y.; Chen, J.; Lu, K.; Wu, W.; Du, C.; Liu, Y.; Wu, T.; Shuai, Z.; Yu, G. Adv. Mater. 2010, 22(37), 4167.

[23] Zhang, S.-L.; Chen, R.-F.; Jiang, H.-J.; Liu, B.; Huang, W. Prog. Chem. 2010, 22, 898 (in Chinese).

(张胜兰，陈润锋，姜鸿基，刘斌，黄维，化学进展， 2010，22， 898.)

[24] Sapochak, L.-S.; Padmaperuma, A.-B.; Cai, X.; Male, J.-L.; Burrows, P.-E. J. Phys. Chem. C 2008, 112, 7989.

[25] Jiang, W.; Yang, W.; Ban, X.; Huang, B.; Dai, Y.; Sun, Y.; Duan, L.; Qiu, Y. Tetrahedron 2012, 68(47), 9672.

[26] He, F.; Tian, L.; Xie, W.; Mao, L.; Gao, Q.; Hanif, M.; Zhang, Y.; Cheng, G.; Yang, B.; Ma, Y. J. Phys. Chem. C 2008, 112, 12024. 
[27] Zhang, X.-Q.; Yang, Z.-C.; Chen, M.-N.; Xu, B.-J.; Zhang, Y.; Chi, Z.-G.; Xu, J.-H. Acta Sci. Nat. Univ. Sunyatseni 2009, 48, 58 (in Chinese.)

(张锡奇, 杨志涌, 陈美娜, 许炳佳, 张艺, 池振国, 许家瑞, 中 山大学学报 (自然科学版), 2009, 48, 58.)

[28] Liu, C.; Li, Y.; Zhang, Y.; Yang, C.; Wu, H.; Qin, J.; Cao, Y. Chemistry 2012, 18(22), 6928.

[29] Sun, J.; Zhong, H.; Xu, E.; Zeng, D.; Zhang, J.; Xu, H.; Zhu, W.; Fang, Q. Org. Electron. 2010, 11(1), 74.

[30] Sun, J.; Lai, H.; Zhong, H.; Fang, Q. Thin Solid Films 2011, 519(22), 7772.

[31] Wei, X.-C.; Bian, Y.-K.; He, D.-Y. J. Funct. Mater. 2007, 12, 1921 (in Chinese). (卫秀成, 边玉坤, 贺德衍, 功能材料, 2007, 12, 1921.)

[32] Xun, L.-M.; Zhang, Q. Mater. Rev. 2007, 10,12 (in Chinese). (孙立梅, 张清, 材料导报, 2007, 10, 12.)

[33] Meng, X.-L.; Zhu, W.-H.; Tian, H. Prog. Chem. 2007, 19, 1671 (in Chinese).

(孟宪乐, 朱为宏, 田禾, 化学进展, 2007, 19, 1671.)

[34] Wang, L.; Jiang, Y.; Luo, J.; Zhou, Y.; Zhou, J.; Wang, J.; Pei, J.; Cao, Y. Adv. Mater. 2009, 21, 4854.

[35] Soh, M.S.; Santamaria, S.A.G.; Williams, E.L.; Pérez-Morales, M.; Bolink, H.J.; Sellinger, A. J. Polym. Sci., Part B: Polym. Phys. 2011, 49(7), 531.

[36] Fan, C.; Li, Y.; Yang, C.; Wu, H.; Qin, J.; Cao, Y. Chem. Mater. 2012, 24(23), 4581

[37] Yook, K. S.; Lee, J.Y. Org. Electron. 2011, 12(10), 1711.

[38] Aizawa, N.; Pu, Y.-J.; Sasabe, H.; Kido, J. Org. Electron. 2012, 13(11), 2235.

[39] Ge, Z.; Hayakawa, T.; Ando, S.; Ueda, M.; Akiike, T.; Miyamoto, H.; Kajita, T.; Kakimoto, M.-A. Adv. Funct. Mater. 2008, 18(4), 584.

[40] Ge, Z.; Hayakawa, T.; Ando, S.; Ueda, M.; Akiike, T.; Miyamoto.H.; Kajita, T.; Kakimoto, M. Chem. Mater. 2008, 20, 2532.

[41] Li, Q.; Li, J.; Ren, H.; Duan, Y.; Gao, Z.; Liu, D. Macromol. Rapid Commun. 2011, 32(9 10), 736.

[42] Elsehner, A.; Heuer, H.-W.; Jonas, F.; Kirehmeyer, S.; Wehrmann, R.; Wussow, K. Adv. Mater. 2001, 13, 1811.

[43] Ryu, D.-W.; Kim, K.-S.; Choi, C.-K.; Park, Y.-I.; Kang, I.-N.; Park, J.-W. Curr. Appl. Phys. 2007, 7(4), 396.

[44] Lee, J.; Park, C. H.; Kwon, J.; Yoon, S.C.; Do, L.-M.; Lee, C. Synth. Met. 2012, 162(21 22), 1961.

[45] Hashimoto, M.; Igawa, S.; Yashima, M.; Kawata, I.; Hoshino, M.; Osawa, M. J. Am. Chem. Soc. 2011, 133 (27), 10348.

[46] Huang, W.-S.; Lin, J.T.; Lin, H.-C. Org. Electron. 2008, 9(5), 557.

[47] Huang, J.; Li, C.; Xia, Y.J. J. Org. Chem. 2007, 72, 8580.

[48] Huang, J.; Liu, Q.; Zou, J.-H.; Zhu.X.-H.; Li, A.-Y.; Li, J.-W.; Wu, Sha.; Peng, J.-B.; Cao.Y.; Xia, R.-D. Adv. Funct. Mater. 2009, 19, 2978.

[49] Zhou, Y.; He, Q.-J.; Yang, Y.; Zhong, H.; He, C.; Sang, G.; Liu, W.; Yang, C.; Bai, F.; Li, Y.-F. Adv. Funct. Mater. 2008, 18, 3299.

[50] Oh, H.-Y.; Kulshreshtha, C.; Kwon, J.H.; Lee, S. Org. Electron. 2010, $11(10), 1624$.
[51] Yang, Y.; Zhou, Y.; He, Q. G. J. Phys. Chem. B 2009, 113, 7745.

[52] Li, Q.; Li, J.; Ren, H.; Duan, Y.; Gao, Z.; Liu, D. Macromol. Rapid Commun. 2011, 32 (9 10), 736.

[53] Ding, J.; Lü, J.; Cheng, Y.; Xie, Z.; Wang, L.; Jing, X.; Wang, F. Adv. Funct. Mater. 2008, 18(18), 2754.

[54] Li, B.-S.; Li, J.; Bo, Z. S. J. Am. Chem. Soc. 2004, 126, 3430.

[55] Carl, A. B.; Zeng, X.-S.; Sylvia, B.; Andrei, S. B.; Martin, R. B.; Anderw, B. Chem. Eur. J. 2007, 13, 6710.

[56] Al-Attar, H. A.; Griffiths, G. C.; Moore, T. N.; Tavasli, M.; Fox, M. A.; Bryce, M. R.; Monkman, A. P. Adv. Master. 2011, 21(12), 2376.

[57] Qin, T.; Ding, J.; Baumgarten, M.; Wang, L.; Mullen, K. Macromol. Rapid Commun. 2012, 33(12), 1036.

[58] Zhang, S.; Turnbull, G. A.; Samuel, I. D. W. Org. Electron. 2012, 13(12), 3091.

[59] Huang, T.; Jiang, W.-L.; Ding, G.-Y.; Wang, J.; Gao, Y.-H.; Ouyang, X.-H.; Zeng, H.-P. Chin. J. Liquid Cryst. Displays 2010, 25, 684 (in Chinese).

(黄涛, 姜文龙, 丁桂英, 汪津, 高永慧, 欧阳新华, 曾和平, 液 晶与显示, 2010, 25, 684.)

[60] Yuen, M.-Y.; Kui, S. C. F.; Low, K.-H.; Kwok, C.-C.; Chui, S. S. Y.; Ma, C.-W.; Zhu, N.-Y.; Che, C.-M. Chem. Eur. J. 2010, 16, 14131.

[61] Ouyang, X.; Chen, D.; Zeng, S.; Zhang, X.; Su, S.; Ge, Z. J. Mater. Chem. 2012, 22(43), 23005.

[62] Huo, Y.-P.; Dai, L.-L.; Huang, B.-H.; Zhang, K.; Fang, Y.-X.; Liu, J. Chin. J. Org. Chem. 2012, 32, 538 (in Chinese).

(霍延平, 戴立立, 黄宝华, 张焜, 方岩雄, 刘军, 有机化学, 2012, 32, 538.)

[63] Yuan, G.-Z.; Huo, Y.-P.; Nie, X.-L.; Fang, X.-M.; Zhao, F.-H. Dalton Trans. 2013, 42, 2921

[64] Yuan, G.-Z.; Huo, Y.-P.; Nie, X.-L.; Fang, X.-M.; Zhu, S.-Z. Tetrahedron 2012, 68(38), 8018.

[65] Wang, X.-P.; Mi, B.-X.; Gao, Z.-Q.; Guo, Q.; Huang, W. Acta Phys. Sinica 2011, 23, 849 (in Chinese).

(王旭鹏, 密保秀, 高志强, 郭晴, 黄维, 物理学报, 2011，23， 849.)

[66] Hou, L.; Duan, L.; Qiao, J.; Zhang, D.; Dong, G.; Wang, L.; Qiu, Y. Org. Electron. 2010, 11 (8), 1344.

[67] Liu, L.; Chen, F.; Xu, B.; Dong, Y.; Zhao, Z.; Tian, W.; Ping, L. Synth. Met. 2010, $160(17 \sim 18), 1968$.

[68] Wang, D.; Wu, Z.; Zhang, X.; Jiao, B.; Liang, S.; Wang, D.; He, R.; Hou, X. Org. Electron. 2010, 11 (4), 641.

[69] Zhang, X.; Wu, Z.; Jiao, B.; Wang, D.; Wang, D.; Hou, X.; Huang, W. J. Lumin. 2012, 132 (3), 697.

[70] Lin, H.-P.; Zhou, F.; Li, J.; Zhang, X.-W.; Yu, D.-B.; Zhang, L.; Jiang, X.-Y.; Zhang, Z.-L. J. Ind. Eng. Chem. 2011, 17(4), 675.

[71] Shirota, Y. J. Mater. Chem. 2005, 15, 75.

[72] Zhang, X.-J.; Xu, Y.-H.; Shi, H.-H. Prog. Chem. 2006, 18, 870 (in Chinese).

(张秀菊, 许运华, 史华红, 化学进展, 2006, 18, 870.)

[73] Kao, M.-T.; Hung, W.-Y.; Tsai, Z.-H.; You, H.-W.; Chen, H.-F.; Chi, Y.; Wong, K.-T. J. Mater. Chem. 2011, 21, 1846.

(Cheng, F.) 